\title{
Uso de las Concesiones Acuícolas de Mar en la Industria Salmonera en Chile
}

\author{
Daniel Vega Salinas \\ Gerente Técnico, DVS Tecnología, Casilla 641, Puerto Varas, Chile. E-mail: danielvegasalinas@gmail.com
}

\section{Resumen}

El presente trabajo es una revisión sobre las concesiones de acuicultura del salmón en la zona sur de Chile, específicamente entre las regiones de Los Lagos y Magallanes. La industria del salmón en Chile ha tenido un incremento en ingresos y producción, que se redujo por el virus ISA entre los años 2008 y 2009, pero tuvo una recuperación posterior. Se comenta sobre los aspectos de costos y tópicos de manejo desde los puntos de vista técnico, económico y legal asociados a la industria del salmón.

Palabras clave: acuicultura, concesiones, producción, salmones.

\begin{abstract}
The present study is a review about the salmon farming concessions in southern Chile, specifically between Lakes and Magallanes regions. The Chilean salmon farming industry has an increase in inputs and production that was decreased due ISA virus between years 2008 and 2009, but it has a recovering the last years. It commented topics about costs, and management under technical, economical and legal view point associated to salmon industry.

Keywords: aquaculture, concessions, production, salmons
\end{abstract}

\section{Introducción}

La salmonicultura en Chile partiendo de cero en poco más de 3 décadas, ha llegado a un nivel que innegablemente es un aporte al desarrollo nacional y en especial a la zona austral del país: volviendo a generar después de su más relevante crisis (virus ISA), cerca de 50.000 empleos directos e indirectos, y generando retornos al país por 2.890 millones de dólares el año 2012, posicionando a la salmonicultura como el cuarto sector exportador del país, pese a sus errores, conflictos y detractores que esta actividad produce.

Para lograr el nivel actual de producción, esta actividad ha tenido que superar una serie de desafíos técnicos, sanitarios, financieros, en infraestructura y de mercados, impuestos por su propio crecimiento, así como también por las exigencias regulatorias y legislativas que se han ido incorporando 
necesariamente a la actividad, tanto de la autoridad gubernamental, así como también de sus propios clientes y consumidores. Por otra parte, han tenido una activa y significativa participación las ONGs y centros de estudios sociales y universitarios, que han venido siguiendo su historia evolutiva, y en muchos casos advirtiendo con mucha antelación los riesgos a la sustentabilidad que esta actividad produce, varios de los cuales se cumplieron cabalmente.

Todas estas observaciones y condicionantes planteadas por estos actores están orientadas a que esta industria sea una actividad Sustentable. Lo que actualmente va mucho más lejos que solo un enfoque medio ambiental del tema; dado que ahora, para que una actividad sea realmente Sustentable, requiere primeramente la empresa productiva tenga un real compromiso en esta Sustentabilidad, haciéndose cargo de todas las externalidades que su actividad produzca; lo que involucra también el aspecto económico y social de sus trabajadores; y que además sea capaz de generar una Responsabilidad Social Empresarial (RSE) frente a la comunidad en la cual se desarrolla su actividad. La mejor forma de graficar este fenómeno nacional, es lo ocurrido en Freirina (localidad ubicada a $30 \mathrm{~km}$ de Vallenar ciudad que se encuentra $645 \mathrm{~km}$ al norte de Santiago), donde se ubicó la planta más grande de América Latina para la crianza y faenamiento de cerdos de la empresa Agrosuper; que a principios del año 2012 y ya en plena operación contaba con cerca de 480 mil animales y una inversión de US\$ 400 millones; los pobladores de Freirina comenzaron en abril del mismo año, una protesta por "malos olores" en la zona, cortando carreteras y provocando disturbios que se extendieron por semanas; lo que finalizo el año 2013 con el cierre indefinido de la planta y con altas pérdidas para la empresa en la operación de cierre y desmantelamiento, además de toda su inversión.

\section{Problemas Coyunturales y Estructurales de la Industria}

En esta actividad son los ciclos biológicos los que restringen la oferta en el corto plazo, dado que el ciclo de vida del Salmón Coho es de 22 meses y para las Truchas cercano a los 25 meses, pero el Salmón Salar es de casi 35 meses, lo que implica en la práctica que las compañías inician la producción sin saber el precio que se logrará al término de cada ciclo, haciendo reaccionar en forma tardía a las empresas productoras, frente a las fluctuaciones de precios altos o bajos. Cuando esta respuesta se produce, normalmente es excedida (overshooting). Si el valor a responder es alto, esta respuesta termina por generar una crisis de rentabilidad por la caída de los precios y viceversa. Este fenómeno no es nuevo y ha ocurrido en toda la historia de la industria desde los años 80 , lo mismo que la volatilidad en el precio, que también es un rasgo de esta industria (Nevasa, 2012). 


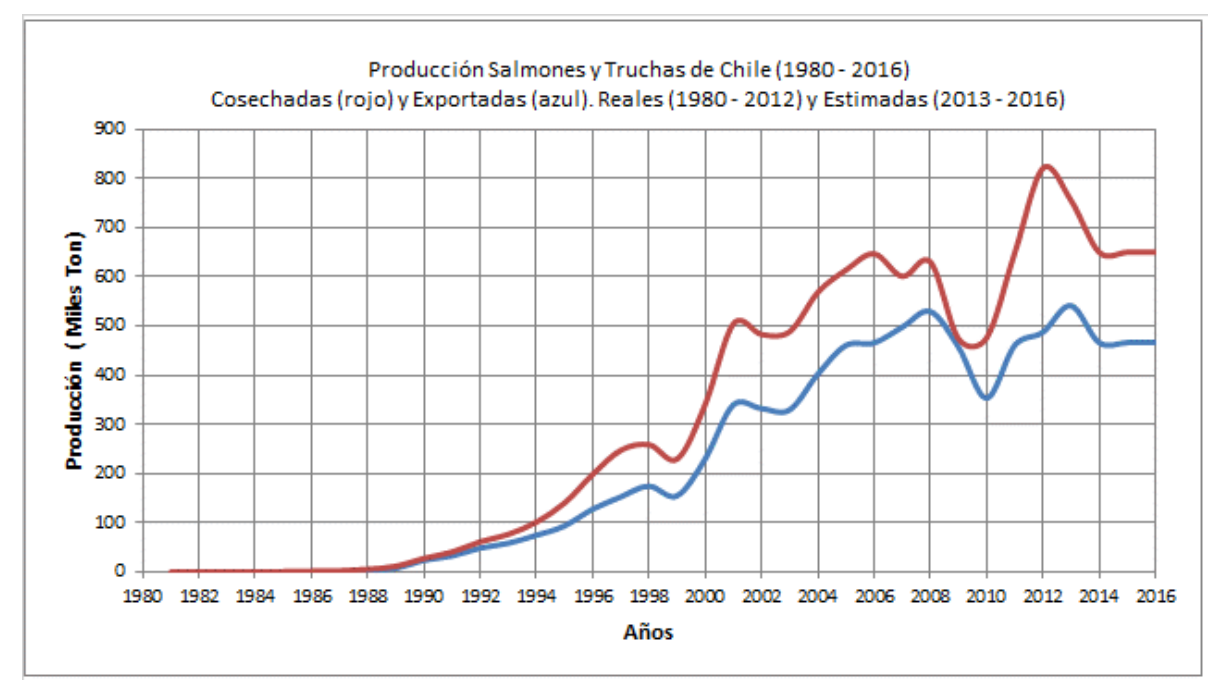

Fig. 1. Producción y Exportación de Salmones y Truchas de Chile. Fuentes: Sernapesca, Subpesca, Claude et al. (2000); Katz et al. (2011); Revista Aqua, Mayo 2013 y estimación propia.

Con la reducción productiva derivada por el virus ISA en Chile (Fig. 1), los precios subieron vigorosamente a nivel mundial durante el año 2011, llegando a un valor de US\$7,59/kg FOB lo que genero ventas por US\$ 2.925 millones con 385.000 ton exportadas. Cuando eso ocurre también la volatilidad de los precios sube. Al año siguiente la sobreoferta nacional superior en un $26 \%$ (488.000 ton exportadas) lo que impulso a la baja el precio internacional (US\$5,93/kg FOB), dando inicio así a la fase del ciclo con baja rentabilidad. Naturalmente la salida de este ciclo obedecerá a una nueva alza de precios, que dependerá de una nueva contracción de la oferta vía disminución de la producción y en un menor grado a un crecimiento de la demanda.

Un estudio presentado por la Corredora de Bolsa, Negocios y Valores S.A. (Nevasa) en noviembre de 2012 sobre "El sector Salmonero" indico que, si bien las empresas salmoneras tiene una historia distinta, ellas (actualmente) tienen características comunes: Stress financiero debido al flujo de caja negativo; elevado endeudamiento; caja limitada; reducción del capital de trabajo como mecanismo de aumentar la caja; y un sostenido aumento de costos más que caída de ventas.

De la descripción de este escenario financiero, ninguno de los aspectos considerados son nuevo para esta industria, y ella ha demostrado tener una fuerte resiliencia, siendo estos para la industria aspectos más bien Coyunturales. Lo que los lleva cada cierto tiempo, cuando ocurren estos escenarios financieros a efectuar fusiones, asociaciones, ventas y compras de empresas, por parte de otras salmoneras o incorporando inversores nuevos. Al parecer, en general para los empresarios del sector, esta situación es más bien evaluada como un aspecto beneficioso, dado que la sanación financiara en la industria, les 
permite tomar una posición más sólida para asumir nuevos desafíos, y por otra parte, ir disminuyendo el número de actores, que algunos han idealizado entre seis o siete grupos relevantes, lo que accedería no solo la consolidación para que las empresas resistan en términos financieros, sino también permitiría reducir los riesgos biosanitarios, al ser menos las compañías cultivando que deban coordinarse entre sí, siendo en tal caso, menor el riesgo de propagación de enfermedades, pero tal vez, el aspecto más importante sería que finalmente le permitiría a la industria alcanzar un consenso sobre niveles de producción Sustentables, lo que en definitiva beneficia a todo el sector.

Por lo tanto, los problemas Estructurales del sector serian a lo menos dos claramente identificados: A) Costos de Producción; y B) Producción Sustentable, que se compone de la Producción Económica, que permita una cierta estabilidad de precios que haga rentable su explotación, y una Producción Biosegura que permita mantener controlado los riesgos biosanitarios y ambientales.

\section{A) Costos de Producción}

El primer aspecto Estructural que debe encontrar una forma de superar la industria, es referida al sostenido aumento de Costos Productivos y Operacionales, que se están produciendo en la actividad derivada de las mayores exigencias normativas, sanitarias, ambientales y sociales tanto de sus trabajadores, como de la comunidad en que está inserta esta industria, así como, la mayor lejanía en que se encuentra desarrollando cada año la actividad, lo que necesariamente incrementara aún más sus costos. Bajo este escenario general deberá continuar los próximos años el desarrollo de la actividad salmonicultora nacional.

El valor inferior de una Producción Sustentable, se genera con la sumatoria de todas las producciones de las empresas. Este valor es de mayor dificultad para llegar a un conceso previo entre los productores, dado que la producción de cada empresa la imponen los planes de Crecimiento y Producción, Costos y Márgenes que cada una tenga definido, y como lo pretenda implementar para cada centro: no es lo mismo sembrar 1,5 millones de smolt o un millón en una concesión, dado que los costos fijos son los mismos. Además se deben tener en cuenta, las restricciones de los Barrios y la densidad de producción, que puede significar en los centros que deben entrar en operación se ubiquen más lejos de las plantas de procesamiento, lo que también incrementa los Costos de transporte general y del alimento, servicios de buceo, redes, respaldo biosanitario y la logística de apoyo y administración.

En general, sobre los Costos nada hace estimar que estos puedan disminuir de alguna manera: las exigencias normativas continuaran, los resguardos biosanitarios se mantendrán o incluso se deberán aumentar, las fiscalizaciones medio ambientales continuaran, y la mayor lejanía en que se encuentra los centros para desarrollar la actividad es un hecho. 
Según Igal Neiman (Salmones Camanchaca) los precios de la harina de pescado, la mano de obra y el combustible en Chile han subido en cerca de un $60 \%$ en la última década. Si consideramos que el costo promedio de producción se estima entre los US $\$ 5,0 / \mathrm{kg}$ y US $\$ 5,5 / \mathrm{kg}$ exportado (14 Octubre, Aqua.cl). Como la venta total del año 2012 fue de US\$ 2.890 millones, se tendría un costo mínimo estimado de US\$ 2.440 millones y los valores que significarían para cada ítem del Costo se muestran en la Tabla 1.

De este detalle de Costos se puede inferir que, un $77 \%$ de ellos se encuentran con una fuerte tendencia hacia el aumento, a lo que se debe agregar un aspecto adicional, y que tiene que ver con la forma en que la industria ha ido enfrentando las necesidades productivas: cada vez las solicitudes de concesiones de las salmoneras se han ido desplazando más hacia el sur del país. Lo que una vez otorgadas hizo que sus operaciones se desplazaran también desde la X a la XI Región y actualmente hacia la XII Región.

A) Producción Sustentable

Determinar el valor de la Producción Económica y de la Producción Biosegura es de compleja estimación y no necesariamente ambos valores pueden ser coincidentes, y además para cada empresa los factores que le permitan su cálculo, tendrá un ponderación diferente de los ítems que los determine. Sin embargo, por todo lo indicado, necesariamente el ciclo 2013 será con una menor producción que la cosechada el 2012 indicada en 821.000 ton (Revista Aqua, Mayo 2013), la que se podría estimar para el ciclo 2013 en una 755.000 ton a cosecha, la que puede llegar a una estabilización entre 600 mil a 650 mil toneladas anuales en los próximos tres a cuatro años, lo que para el Subsecretario de Pesca, Pablo Galilea, le permitiría (a la industria) mejorar su performance sanitaria (Fig. 1).

Se puede indicar que en la práctica la Producción Sustentable se ajusta con los precios y/o la bioseguridad medio ambiental en que los peces se encuentren afectados, generando el valor de la barrera superior a las producciones excesivas. Lo que a su vez depende de una multiplicidad de factores internos y externos: como los aspectos biosanitarios de la producción entren en crisis; que las fiscalizaciones vaya disminuyendo el número de concesiones operativas; que la volatilidad del precio se mantenga alta y no se disponga de una estrategia para moderar el impacto de este riesgo; que Noruega aumente su producción; que a Chile se le dificulte en el corto y mediano el acceso a los mercados de Estados Unidos y Japón.

Al respecto de la bioseguridad medio ambiental en el año 2009 la Autoridad emitió la Res. Ex. Nº 1449/2009, para mitigar la aparición de nuevos brotes ISA, donde se fijaron densidades máximas de cosecha: Salmón del Atlántico $17 \mathrm{Kg} / \mathrm{m3}$; Trucha y Coho: $12 \mathrm{Kg} / \mathrm{m3}$; y Chinook: $10 \mathrm{Kg} / \mathrm{m3}$. Lo que en la práctica se tradujo en el ingreso de un número menor de peces a ingresar por cada centro. Lo que llevo a que el año 2010 las densidades de cultivo presentaron una menor densidad: Salmón del Atlántico 10-15 
Kg/m3; Salmón Coho 9-15 Kg/m3; y Trucha Arco iris: 8-15 Kg/m3. Con estas prácticas la industria inicia el aumento de sus producciones posterior a la crisis del ISA, pero de una manera más Sustentable.

Tabla 1, Estructura Estimada de Costos Industria Salmonera Chile. Modificado de Alvial (2002); Bañados \& Alvial (2007).

\begin{tabular}{|c|c|c|c|}
\hline Ítems & $\%$ & Millones US \$ & Tendencia \\
\hline Alimentos & $38,0 \%$ & 927,2 & Aumento \\
\hline Mano de Obra & $20,0 \%$ & 488,0 & Aumento \\
\hline Flete Aéreo Internacional & $9,2 \%$ & 224,5 & Aumento \\
\hline Pigmentos & $8,0 \%$ & 195,2 & Desconocida \\
\hline Empaques & $4,0 \%$ & 97,6 & Desconocida \\
\hline Mantención & $3,0 \%$ & 73,2 & Mantenerse \\
\hline Salud & $2,7 \%$ & 65,9 & Aumento \\
\hline Fletes Terrestres & $2,6 \%$ & 63,4 & Mantenerse \\
\hline Fletes Marítimos Internacional & $2,2 \%$ & 53,7 & Mantenerse \\
\hline Materiales e Insumos & $2,0 \%$ & 48,8 & Desconocida \\
\hline Servicios financieros & $1,5 \%$ & 36,6 & Aumento \\
\hline Operaciones y Logística & $1,5 \%$ & 36,6 & Aumento \\
\hline Redes & $1,3 \%$ & 31,7 & Aumento \\
\hline Energía y Combustible & $1,0 \%$ & 24,4 & Aumento \\
\hline Buceo & $1,0 \%$ & 24,4 & Aumento \\
\hline Fletes Marítimo Nacional & $1,0 \%$ & 24,4 & Aumento \\
\hline Arriendo de Máquinas y Equipos & $0,5 \%$ & 12,2 & Desconocida \\
\hline Frigorífico & $0,5 \%$ & 12,2 & Mantenerse \\
\hline Total Costo & $100 \%$ & 2.440 & $77,2 \%$ Aumento \\
\hline
\end{tabular}

En Agosto del 2012 la Subsecretaria de Pesca y Acuicultura (Subpesca) hace la primera Propuesta para el Reglamento Densidades con Score de Riesgo y Plan de Manejo, considerando las variables ambientales del centro y del Barrio, basado en condiciones oceanográficas, batimétricas, entre otras. La propuesta determina que el resultado de esta evaluación se utilizará para determinar el número de peces a sembrar en el periodo productivo siguiente, y la clasificación de bioseguridad (score de riesgo) se realizará al finalizar un periodo productivo. Se piensa que su aplicación podría impactar significativamente en algunas siembras, en que los centros tuvieron un mal desempeño sanitario, dejándolas inviables por costo de producción. 
Esta propuesta de regulación establece para los Barrios con densidades superiores al actual estándar de Sernapesca, aplicar un factor de protección evitando densidades similares a la época de crisis (ISA), que para Salar el rango fluctuaría entre 15 y $17 \mathrm{~kg} / \mathrm{m} 3$, y este valor máximo solo asociado a Barrios con buena condición sanitaria. Los valores de densidades serian sensibilizados con los resultados de un estudio de costos que permitirá contar con bandas de densidades por especie, en función del perfil de la industria, costos de producción y precios. Manteniendo siempre las mejores condición sanitaria en los centros y Barrios.

\section{Valor de las Concesiones Acuícolas}

Según Troya et al. (2011) las principales características de una empresa para llegar a ser competitiva en esta industria son: la cantidad de concesiones que disponga una empresa salmonera (mar y lagos); las estrategias implementadas para el manejo de los Costos de Producción; y la capacidad para innovar, emprender y utilizar su knowhow. Pero indudablemente, sin la primera característica, aun cuando puedan existir las capacidades para las otras dos, ellas solas carecen de sentido en esta industria. Por lo tanto, el principal activo que sustenta la actividad de las empresas salmoneras, son las concesiones acuícolas, de las cuales analizaremos en este trabajo las de Mar.

Tan real es su valor, que después de la crisis del ISA se promulga la ley № 20.434 en que las concesiones son tratadas con un sistema de registro similar al de los Conservadores de Bienes Raíces, fortaleciéndose los derechos de los titulares de las concesiones, facilitando la transferencia de éstas, eliminando la autorización previa de la subsecretaría para tal efecto. Pero siendo lo más importante en esta legislación, que las concesiones pueden ser otorgadas como en garantía de créditos. No permitiéndose la caducidad de las concesiones, sobre las cuales existan embargo $u$ otras medidas judiciales fundadas en la prenda.

Y por otra parte, después de la zonificación de las Áreas Aptas para la Acuicultura (AAA), donde quedaron zonas definidas para las distintas actividades económicas, resultando muchas zonas del borde costero excluidas para la actividad salmonera, lo que finalmente determinó que los sitios aptos para esta industria sean cada vez más menos. Otro aspecto que permite que las concesiones tengan un alto valor, es que la producción Intensiva está llegando a sus límites en el norte de Europa. Noruega no ha entregado nuevas concesiones salmoneras desde comienzo de esta década, mientras Irlanda y Escocia, evidencian crecientes regulaciones y mayores costos de producción (Igor y Díaz, 2007), y en Canadá lograr una concesión tiene muchas trabas relacionada con los acuerdos que se deben lograr previamente con las comunidades originarias, antes de que la concesión sea otorgada. 


\section{Cobros de Patentes}

En la actualidad, por cada hectárea de concesión las salmoneras pagan anualmente unos \$400 mil (10 UTM). Aun cuando algunas de las primeras concesiones otorgadas fueron por el máximo de 50 hectáreas, otras empresas en cambio, al no existir definición en las ley sobre si los fondeos de las jaulas, deben o no quedar dentro de la concesión otorgada, solicitaron exactamente por el área que ocupaba solo el tren de jaulas, lo que significo otorgamiento de concesiones por superficie de 1,5 hectáreas. Según ciertos cálculos estimativos señalan que en promedio las concesiones tendrían unas diez hectáreas, lo que supone una patente de unos \$3,2 millones por cada concesión. Pablo Longeira, Ministro de Economía señalo en su momento "Creemos que son muy bajas, y ahí podemos tener ingresos que nos permitan invertir en investigación. La idea es acompañar el desarrollo de esta industria no solamente con una institución, sino que también haciendo inversiones".

Se considera en la ley № 20.434 un aumento progresivo de este cobro a 10 UTM a partir de 2013; 12 UTM el 2014; 14 UTM el 2015; 17 UTM el 2016 y 20 UTM a partir del año 2017.

\section{Otorgamiento, Uso y Caducidad de las Concesiones}

Antes de la moratoria de concesiones (2010 - 2015) posterior al ISA, en promedio el otorgamiento de una concesión demoraba entre 3 y 5 años. Una vez otorgada la concesión la ley sanciona el no uso de las concesiones de acuicultura con la caducidad, pero existe una contradicción en la regulación, que se reconoce desde el mismo Gobierno: "Se debe propiciar la rotación de uso de concesiones por temas ambientales y sanitarios y, por otra parte, no existe una ley de reasignación de concesiones, por lo cual, la concesión caducada simplemente se pierde para el sector". A lo que se debe contemplar el creciente rechazo a este tipo de actividad, haciendo cada vez más complejo de creación de nuevas áreas para las concesiones de acuicultura, por lo tanto, en la práctica cada concesión perdida por caducidad difícilmente será reemplazada, dado que ésta no puede ser reasigna inmediatamente, por no existir un procedimiento para ello, sino que cualquiera que desee obtener ese sector, liberado por la caducidad de una concesión, tendrá que someterse a una nueva tramitación partiendo desde sus inicios, con la presentar una Declaración de Impacto Ambiental al Servicio de Evaluación Ambiental (SEA).

Con las modificaciones realizadas a la ley de Pesca y Acuicultura del año 2010, las nuevas concesiones poseen un plazo de permanencia de 25 años renovables por igual plazo, a menos que la mitad de los informes ambientales hayan sido negativos; a diferencia de las concesiones vigentes que mantienen una duración indefinida. El titular de una concesión deberá iniciar sus operaciones dentro del plazo de un año, y se entenderá que existe operación cuando la actividad del centro es igual o superior a los niveles 
mínimos de operación por especie y área que se establezcan mediante reglamento. Además, se entiende que existe operación cuando el centro debe cumplir con el período de descanso o paralización por resolución de la autoridad.

También la ley señala que el titular de una concesión podrá paralizar operaciones por dos años consecutivos, pudiendo solicitar a la Subsecretaría de Marina o de Pesca, la ampliación de dicho plazo por el equivalente al doble del tiempo de operación que haya antecedido a la paralización, con un máximo de cuatro años. Para tales efectos se considerará incluida en la operación el plazo que transcurra entre una cosecha y la próxima siembra, el que será fijado por reglamento y no podrá ser inferior a seis meses, como también el plazo que corresponda a un período de descanso o paralización por resolución de la autoridad.

Este hecho ha llevado a ciertas empresas a utilizar una práctica, que es fuertemente cuestionadas por la Subsecretaría de Pesca y Acuicultura: "Debe reconocerse que estamos presenciando además una práctica de algunas empresas de no usar las concesiones, acudiendo a las normas ambientales y sanitarias, como una estrategia comercial (para mantenerlas en su poder), lo que es cuestionable desde el punto de vista del acceso a las concesiones". El Gobierno desde el año 2012 comenzó a aplicar la caducidad para las concesiones acuícolas, que no cumplan con los estándares exigidos por la autoridad y que se mantengan sin operar por un período de dos años.

Pablo Galilea, Subsecretario de Pesca indica: "No quiero adelantar nada, pero hay que buscar un mecanismo inteligente que cree un incentivo para producir en las concesiones o definitivamente optar por su transferencia, siempre y cuando no afecte la cuestión sanitaria", y explica que pese a que reconoce el alto interés que genera en la industria el futuro de las concesiones que no se utilizan, prefiere tomar una actitud de mesura frente a los futuros cambios, a lo cual el empresariado salmonero también ha reaccionado con cautela.

Por causa del período de moratoria en las regiones de Los Lagos y de Aysén, el problema es que en estas zonas la moratoria para la entrega de concesiones está vigente desde Abril del 2010 hasta Abril del 2015, José Miguel Burgos, jefe de la División de Acuicultura de la Subsecretaría de Pesca, señala que "sólo estamos haciendo relocalizaciones en estas dos regiones. Aquí nuestro eslogan para esas regiones es: No más concesiones, sino que mejores concesiones", y pese a que se retomará la ley de caducidad de concesiones salmoneras, en los centros que no se pueden traspasar, el escenario no cambiará mucho en el corto plazo para las firmas pequeñas y medianas. 


\section{Relocalización de Concesiones}

Debido a la urgencia producida por la crisis del ISA en la región de Los Lagos y de Aysén, y dado que los titulares de centros de cultivo necesitaban reubicarse en áreas donde la coordinación sea más fácil con otros titulares o bien áreas que por sus características sean más apropiadas al ejercicio de la actividad, por ejemplo, por mayores profundidades. Se concedió la posibilidad de relocalizar la concesión, por una sola vez entre Abril del 2010 y Abril del 2015 renunciando a ella, y condicionado a la obtención de una concesión en la nueva ubicación dentro de la misma Región.

Se dio preferencia en la relocalización a las solicitudes cuyo objeto sea reemplazar una concesión cuyo titular haya tenido una producción de Salmón del Pacífico o Trucha Arcoiris que represente a lo menos el $50 \%$ de su producción total, en los dos años anteriores a la fecha de la solicitud de relocalización. Lo que se vio como una buena alternativa para los pequeños acuicultores.

Sobre esta relocalización, aun cuando la Ley General de Pesca y Acuicultura, señala que es responsabilidad del concesionario la mantención de la limpieza y el equilibrio ecológico de la zona concedida, cuya alteración tenga como causa la actividad acuícola, indicando que deberán reglamentarse las medidas de protección del medio ambiente, para que los establecimientos que exploten concesiones de acuicultura operen en niveles compatibles con la capacidad de los cuerpos de agua marítimos; $\sin$ embargo la Ley № 20.434 en su Artículo 5, que regula las reubicaciones de las concesiones, no hace mención alguna sobre la manera que deba quedar ambientalmente el centro que se deja. Solo señala que toda relocalización de concesiones deberá someterse al Sistema de Evaluación de Impacto Ambiental, y que la concesión de reemplazo quedará sometida al mismo régimen que la concesión original.

Previamente para lograr el mismo efecto de mitigación a la crisis del ISA se establecieron las Áreas de Manejo Sanitario o "Barrios" (Resolución N450/09, enero 2009), los cuales tienen como finalidad agrupar sectores donde se realizan diversas actividades de la acuicultura en un sector determinado y en acuerdo con todos los usuarios del Barrio, establecer un periodo fijo para todos los usuarios (del sector) de descanso. Las que se implementaron con la reubicación de los centros de cultivo, del modo indicado, o de la transferencia mediante el traslado ya no de la concesión misma sino de su titular a otra zona donde adquiere un nuevo centro. En el caso de la región de Los Lagos, sólo se permitió la relocalización de concesiones para integrar o formar parte de un área de manejo sanitario, y en el caso de la región de Aysén sólo se otorgarán nuevas concesiones dentro de áreas de manejo sanitario que hayan sido fijadas por la Subsecretaría de Pesca en el plazo fijado. 
El titular de dos o más concesiones de acuicultura puede fusionarlas, sometiéndose a las condiciones antes señaladas. También la ley permite dividir una concesión para fusionar una o más de sus fracciones a otras concesiones de su misma titularidad. En el caso de concesiones de acuicultura ubicadas en el Fiordo de Aisén o en la comuna de Chaitén de la Décima Región de Los Lagos, cada una de las fracciones que resulten de una división podrá ser objeto de relocalización.

Otro aspecto complementario a las relocalizaciones es la exigencia para sembrar determinada por Sernapesca, donde es obligación tener al menos una jaula dentro de la concesión por tren de jaulas. Trenes fuera de la concesión han tenido que ser reubicados con el consiguiente gasto, y terminan muchas veces en lugares no buenos del punto de vista corrientes o profundidades.

\section{Nuevas Concesiones en la XII Región}

De acuerdo al Gobierno y la industria, la única salida para la salmonicultura sería el otorgamiento de nuevas concesiones en la zona de Magallanes, como una nueva zona de crecimiento para la salmonicultura, para lo cual el Gobierno estudia la ley que permitiría licitar las futuras concesiones acuícolas. La Autoridad proyecta otorgar unas 100 nuevas concesiones en Magallanes a más tardar a principios de 2014.

"Se está estableciendo una agenda clara para dar certezas respecto a cómo se van a aplicar las caducidades de las concesiones; cómo se van asignar las nuevas áreas de concesiones a través de licitación; cómo y cuándo vamos a entregar las nuevas áreas en Aysén y Magallanes, y cuáles serán las medidas que vamos a cambiar debido a la revisión que estamos haciendo", explica el subsecretario de Pesca y Acuicultura, Pablo Galilea. Por todo lo indicado, la autoridad está monitoreando de cerca el uso que se les da a las concesiones, e incluso evalúa un eventual cambio en la normativa, si esa es la mejor forma de optimizar el uso de las concesiones.

Sin embargo, Katz, et al. (2011) señala al respecto que "pese a que se supone que muchas de estas nuevas zonas de cultivo están más libres de la amenaza de patógenos que las zonas más sobrepobladas, debemos admitir que la extrema movilidad y agresividad de los factores patógenos, y la posibilidad de que se desarrollen nuevas cepas mutantes de muchos de los mismos, arrojan dudas sobre la posibilidad de que por seleccionar zonas más alejadas de localización productiva, las firmas nuevas tengan un futuro sanitario más protegido". 


\section{Postura Empresarial}

Como se ha indicado el número de concesiones que cada empresa maneja constituye el activo de mayor importancia, entre otras cosas, porque le permite programar escalonadamente su calendario de actividades y descansos usando las concesiones en los distinto Barrios en que la empresa tiene presencia, por lo que ser dueña del mayor número de concesiones implica una ventaja importante para la empresa.

Esta situación llevo a un quiebre al interior de la industria y al abandono de la Asociación de Productores de Salmón, por parte de las salmoneras más pequeñas, formando en Junio del 2009 la Asociación de Productores de Salmón Coho y Truchas (Acotruch), por los productores que en su mayoría producían Truchas, al sentirse menoscabadas por parte de las empresas salmoneras mayores, en el proceso de restructuración que sufrió el sector por la crisis del ISA.

Víctor Hugo Puchi, Presidente de AquaChile y ex Director de SalmonChile, indica que "En la época de la crisis (virus ISA) hubo empresas que viendo que los productores antiguos fuimos financieramente muy afectados, imaginaron la alternativa de ocupar nuestro espacio. Hubo potenciales entrantes que querían más concesiones, más producción, que querían sangre. Y nosotros queríamos una industria más segura. El tiempo pasó y hoy el futuro nos une.... Queremos una industria más segura, no importa que se pierdan concesiones o se castiguen capacidades de producción cuando los límites biológicos así lo aconsejen... Ya no se otorgan nuevas concesiones y las que están sanitariamente mal ubicadas deben relocalizarse. Y si ello significa un costo en el corto plazo, lo vamos a pagar con gusto para tener una industria más segura."

En esta línea José Ramón Gutiérrez, presidente de Multiexport Foods, indica que las nuevas regulaciones no resuelven el problema real, que son las más de 1.200 concesiones otorgadas en el sur de Chile, que superan la capacidad natural de producción del área.

\section{Distribución de las Concesiones por Empresas}

Una primera aproximación sobre la distribución de las concesiones por empresa, se muestra en la Tabla 2 que se construye a partir de la Guía de Instalaciones Acuícolas en Chile 2010, para las Regiones X y XI elaborado por Intrafish. Un hecho significativo es que 8 empresas concentran 700 concesiones, que corresponde al $66 \%$ de las concesiones, y ellas producirían el 51\% de la Producción estimada para el Ciclo 2013. 
Sustainability, Agri, Food and Environmental Reasearch 2(1): 1-35, 2013.

Tabla 2. Concesiones en regiones de Los lagos y Aysén (2010) y producción estimada por empresas (ciclo 2013).

\begin{tabular}{|c|c|c|c|c|}
\hline \multirow[t]{2}{*}{ Empresas } & \multicolumn{2}{|c|}{ Concesiones } & \multicolumn{2}{|c|}{ Producción } \\
\hline & Cantidad & $\%$ & Toneladas & $\%$ \\
\hline Aquachile & 149 & 14,1 & 91000 & 12.6 \\
\hline Marine Harvest & 145 & 13,7 & 53000 & 7,3 \\
\hline Multiexport & 85 & 8,0 & 44000 & 6,1 \\
\hline Holding and Trading (ex unimarc) & 74 & 7,0 & 12000 & 1,7 \\
\hline Camanchaca & 71 & 6,7 & 41000 & 5,7 \\
\hline Los Fiordos & 70 & 6,6 & 63000 & 8,7 \\
\hline Mainstream & 54 & 5,1 & 60000 & 8,3 \\
\hline Acuinova + Pesca Chile & 52 & 4,9 & 34000 & 4,7 \\
\hline Otros titulares & 45 & 4,2 & 1000 & 1,4 \\
\hline Yadran & 39 & 3,7 & 23000 & 3,2 \\
\hline Invertec & 28 & 2,6 & 19000 & 2,6 \\
\hline Blumar (Itata + El Golfo) & 26 & 2,5 & 49000 & 6,8 \\
\hline Salmones antártica & 26 & 2,5 & 21000 & 2,9 \\
\hline Ventisqueros & 23 & 2,2 & 25000 & 3,5 \\
\hline Pacific Star & 23 & 2,2 & 10000 & 1,4 \\
\hline Cupquelan & 19 & 1,8 & 18000 & 2,5 \\
\hline Frio Sur & 19 & 1,8 & 21000 & 2,9 \\
\hline Australis mar & 17 & 1,6 & 32000 & 4,4 \\
\hline Cultivos Marinos Chiloé & 16 & 1,5 & 18000 & 2,5 \\
\hline Tornagaleones + Marine Farm & 13 & 1,2 & 25000 & 3,5 \\
\hline Congelados Pacífico & 10 & 0,9 & 9000 & 1,2 \\
\hline Caleta Bay & 8 & 0,8 & 4500 & 0,6 \\
\hline Humboldt & 7 & 0,7 & 8000 & 1,1 \\
\hline Ice Val & 5 & 0,5 & 3000 & 0,4 \\
\hline Sea Salmon & 4 & 0,4 & 600 & 0,1 \\
\hline Salmones Aysén & 2 & 0,2 & 17000 & 2,4 \\
\hline Totales & 1030 & 100,0 & 702100 & 100,0 \\
\hline
\end{tabular}

Una segunda aproximación y de mucha más difícil determinación es conocer el número de Centros se encuentran en operación anualmente, al respecto existe la estimación de Gárate (2011), que parte de un número mayor de Concesiones otorgadas, para la X Región 539 concesiones; y para XI Región 635 
concesiones, lo que totaliza 1.174 concesiones, e incluye para la XII Región 57 Concesiones, totalizando 1.231 concesiones; su informe "Tendencias en la Productividad del Cultivo de Salmonídeos en Chile" señala que en Abril del 2011 habían 245 centros Activos y que estos representaban el 30\% de las Concesiones, lo que daría una producción de 2.650 Ton/Centro/año.

Otra estimación con respecto a la cantidad de centros que se requieren utilizar para la producción salmonera en Chile, es el citado en el estudio "Creciendo en base a los recursos naturales, "tragedias de los comunes" y el futuro de la industria salmonera chilena" (Katz et al. 2011) y que se muestra en la Tabla 3.

Tomado ambos antecedentes se puede estimar que para una Producción de 755.000 ton (producción estimada para el 2013), se requirieren una cantidad de Centros Activos que varían entre 264 según datos Garate (2011) y más de 750 centros utilizando el promedio de Katz, et al. (2011), siendo este último valor desestimado, porque significaría sembrar una cantidad menor a 400.000 smolt por centro. En la Tabla 3 se muestra el detalle una estimación por empresa que se elabora en este trabajo.

Tabla 3. Cuadro modificado de Biomasa Promedio por Centro Productivo, Chile. (Katz et al., 2011). Fuente: EWOS, Comparación de resultados productivos en salmón atlántico. Noruega-Chile. Mimeo, Puerto Varas, Noviembre, 2007.

\begin{tabular}{|l|c|}
\hline Área de cultivo & Biomasa (Tonelada por centro) \\
\hline Estuario del Reloncaví & 1.142 \\
\hline Chiloé centro & 1.136 \\
\hline Melinka & 1.106 \\
\hline Hornopirén & 1.079 \\
\hline Seno del Reloncaví & 1.076 \\
\hline Cisne & 892 \\
\hline Chiloé sur & 859 \\
\hline Aysén & 757 \\
\hline Promedio & 1.006 \\
\hline
\end{tabular}

La Tabla 4 tiene el objeto solo de entregar una visión referencial, dado que es muy difícil determinar precisamente los centros que se encuentra recibiendo smolt o los que están terminando su ciclo en cada empresa, por lo tanto, este número de centros activos de 262 puede estar subestimado en un porcentaje de encaje estimado en un $8 \%$, lo que nos puede indicar que el número de centros operativos en la X y XI 
Región puede estar más cercano a los 282 más los de la XII Región que son 21, se llega a un total de 303 centros, para una producción estimada de 755.000 toneladas a cosecha (720.000 ton de las X y XI Regiones +35.000 ton de la XII Región), lo que entrega finalmente un promedio estimado por centro de 2.460 toneladas.

Sin embargo, independiente del valor definitivo que se produzca por centro, está claro que no se vislumbra en el corto plazo, una crisis por disponibilidad de concesiones otorgadas a las empresas salmoneras, menos aún después de las nuevas adquisiciones, asociaciones y fusiones que se han producido o que se encuentran en evaluación para realizarse entre las empresas del sector (Tabla 5).

\section{Situación Ambiental de las Concesiones}

Otro enfoque que se debe efectuar con las concesiones, tiene relación a la situación ambiental que ellas están evidenciando, después de la nueva reglamentación implementada posterior al ISA.

Lo primero que se desprende es que hay una diferencia no menor entre lo que se divulgó como concesiones para la X y XI Regiones, por la Guía de Instalaciones Acuícolas en Chile 2010, para las Regiones X y XI elaborado por Intrafish, el que entrega 1.060 como el número de Concesiones. Sin embargo en la Propuesta para el Reglamento Densidades con Score de Riesgo y Plan de Manejo, presentado la Subsecretaria de Pesca y Acuicultura en Agosto del 2012, indica que el número total de concesiones de Mar son 1.231; registrando un 43,8\% en la X Región, un 51,6\% en la XI Región, y un 4,6\% para la XII Región (Figura 2). Las que disminuyen a 978 Concesiones, con el último informe de Sernapesca (Agosto 2013); teniendo en este registro la mayor cantidad de concesiones en la X Región con un 57,5\% (562 Concesiones), y un 40,4\% en la XI Región (395 Concesiones); no siendo relevante el aporte de la XII Región con solo un 2,1\% (21 Concesiones). Cantidad de concesiones que son un 10,7\% menos que lo castrado el 2010 y un 22,7\% que lo registrado el 2012, para las Regiones X y XI (Tabla 6).

Una mirada general se muestra en la Tabla № 7, la que está basada en el Informe Ambiental que levanta trimestralmente en su página web el Servicio Nacional de Pesca (Sernapesca), la que toma la información actualizada hasta el mes de Julio del 2013 y fue publicado en el mes de Agosto. Para mejor entender la distribución de las Categorías en que se clasifican las concesiones, se muestra la Tabla 8.

Una segunda mirada de las condiciones ambientales de las concesiones, es revisando las estadísticas de evaluación conforme a los 5 conceptos de sus condiciones ambientales y/o situación que la concesión se encuentra. La descripción de la evaluación conceptual se detalla en la Tabla 9.

Los resultados estadísticos de la situación medio ambiental de las concesiones, se muestran en la Tabla 10. El 15,3\% de ellas se encuentran en condición de rechazo medio ambiental, y el 8,1\% en Bitácora, que 
Sustainability, Agri, Food and Environmental Reasearch 2(1): 1-35, 2013.

corresponde a la práctica de no usar las concesiones, acudiendo a las normas ambientales y sanitarias, que es cuestionada por la autoridad, además tampoco en ellas se conocería a cabalidad el real estado medio ambiental de estas concesiones.

Tabla 4. Concesiones en regiones de Los lagos y Aysén (2010) y producción estimada por empresas (ciclo 2013).

\begin{tabular}{|c|c|c|c|c|c|c|c|}
\hline \multirow[t]{2}{*}{ Empresas } & \multicolumn{2}{|c|}{ Concesiones } & \multicolumn{2}{|c|}{ Producción } & \multirow[t]{2}{*}{ Ton/Centro } & \multicolumn{2}{|c|}{ Centros } \\
\hline & Cantidad & $\%$ & Toneladas & $\%$ & & Activos & Disponibles \\
\hline Marine Harvest & 145 & 13,7 & 53000 & 7,3 & 2800 & 19 & 126 \\
\hline AquaChile & 149 & 14,1 & 91000 & 12,6 & 3300 & 28 & 121 \\
\hline Multiexport & 85 & 8,0 & 44000 & 6,1 & 3300 & 13 & 72 \\
\hline Holding and Trading (ex unimarc) & 74 & 7,0 & 12000 & 1,7 & 2000 & 6 & 68 \\
\hline Camanchaca & 71 & 6,7 & 41000 & 5,7 & 3000 & 14 & 57 \\
\hline Los Fiordos & 70 & 6,6 & 63000 & 8,7 & 3300 & 19 & 51 \\
\hline Acuinova + Pesca Chile & 52 & 4,9 & 34000 & 4,7 & 2800 & 12 & 40 \\
\hline Otros titulares & 45 & 4,2 & 10000 & 1,4 & 1800 & 6 & 39 \\
\hline Mainstream & 54 & 5,1 & 60000 & 8,3 & 3300 & 18 & 36 \\
\hline Yadran & 39 & 3,7 & 23000 & 3,2 & 2200 & 10 & 29 \\
\hline Trusal & 30 & 2,8 & 10000 & 1,4 & 2000 & 5 & 25 \\
\hline Invertec & 28 & 2,6 & 19000 & 2,6 & 2000 & 10 & 19 \\
\hline Ventisqueros & 23 & 2,2 & 25000 & 1,4 & 2200 & 5 & 18 \\
\hline Salmones Antártica & 26 & 2,5 & 21000 & 2,9 & 2200 & 10 & 16 \\
\hline Pacific Star & 23 & 2,2 & 10000 & 2,9 & 2200 & 10 & 13 \\
\hline Frio Sur & 19 & 1,8 & 18000 & 2,5 & 2500 & 7 & 12 \\
\hline Cupquelan & 19 & 1,8 & 21000 & 2,9 & 2500 & 8 & 11 \\
\hline Blumar (Itata + El Golfo) & 26 & 2,5 & 49000 & 6,8 & 3000 & 16 & 10 \\
\hline Cultivos Marinos Chiloé & 16 & 1,5 & 18000 & 2,5 & 2200 & 8 & 8 \\
\hline Caleta Bay & 8 & 0,8 & 4500 & 0,6 & 2200 & 2 & 6 \\
\hline Australis Mar & 17 & 1,6 & 32000 & 4,4 & 2800 & 11 & 6 \\
\hline Congelados Pacífico & 10 & 0,9 & 9000 & 1,2 & 1800 & 5 & 5 \\
\hline Tornagaleones + Marine Farm & 13 & 1,2 & 25000 & 3,5 & 3000 & 8 & 5 \\
\hline Humboldt & 7 & 0,7 & 8000 & 1,1 & 2500 & 3 & 4 \\
\hline Ice Val & 5 & 0,5 & 3000 & 0,4 & 2000 & 2 & 4 \\
\hline Sea Salmon & 4 & 0,4 & 600 & 0,1 & 1000 & 1 & 3 \\
\hline Salmones Aysén & 2 & 0,2 & 17000 & 2,4 & 2500 & 7 & -5 \\
\hline Totales & 1060 & 100 & 721100 & 100 & 2633 & 262 & 798 \\
\hline
\end{tabular}


Sustainability, Agri, Food and Environmental Reasearch 2(1): 1-35, 2013.

Tabla 5. Concesiones regiones de Los Lagos y Aysén (2010) y estimación de concesiones a partir de la producción estimada por empresas (ciclo 2013).

\begin{tabular}{|c|c|c|c|c|}
\hline \multirow[t]{2}{*}{ Empresas } & \multicolumn{2}{|c|}{ Concesiones } & \multicolumn{2}{|c|}{ Producción } \\
\hline & Cantidad & $\%$ & Toneladas & $\%$ \\
\hline Marine Harvest + Acuinova + Pesca Chile (evaluación) & 197 & 18,6 & 87000 & 12,1 \\
\hline AquaChile & 149 & 14,1 & 9100 & 12,6 \\
\hline Multiexport & 85 & 8,0 & 44000 & 6,1 \\
\hline Holding and trading (ex Unimarc) & 74 & 7,0 & 12000 & 1,7 \\
\hline Camanchaca & 71 & 6,7 & 41000 & 5,7 \\
\hline Los Fiordos & 70 & 6,6 & 63000 & 8,7 \\
\hline Mainstream + Cultivos Marinos Chiloé & 70 & 6,6 & 7800 & 10,8 \\
\hline Pacific Star + Trusal & 53 & 5,0 & 20000 & 2,8 \\
\hline Cupquelan + Invertec (negociación) & 47 & 4,4 & 40000 & 5,5 \\
\hline Otros titulares & 45 & 4,2 & 10000 & 1,4 \\
\hline Yadran & 39 & 3,7 & 23000 & 3,2 \\
\hline Ventisqueros + Congelados del Pacífico & 33 & 3,1 & 34000 & 4,7 \\
\hline Salmones Antártica & 26 & 2,5 & 21000 & 2,9 \\
\hline Blumar (Itata + El Golfo) & 26 & 2,5 & 49000 & 6,8 \\
\hline Frio Sur & 19 & 1,8 & 18000 & 2,5 \\
\hline Australis Mar & 17 & 1,6 & 32000 & 4,4 \\
\hline Tornagaleones + Marine Farm & 13 & 1,2 & 25000 & 3,5 \\
\hline Caleta Bay & 8 & 0,8 & 4500 & 0,6 \\
\hline Humboldt & 7 & 0,7 & 8000 & 1,1 \\
\hline Ice Val & 5 & 0,5 & 3000 & 0,4 \\
\hline Sea Salmon & 4 & 0,4 & 600 & 0,1 \\
\hline Salmones Aysén & 2 & 0,2 & 17000 & 2,4 \\
\hline Totales & 1060 & 100 & 721100 & 100 \\
\hline
\end{tabular}

Conforme a los datos publicados por Sernapesca al ser segmentando por Regiones, vemos que actualmente la X Región (Tabla 11) tiene el 9,6\% de las concesiones en condición de rechazo medio ambiental, y el 5,2\% en la condición de Bitácora apoyada en las normas ambientales y sanitarias. Otro dato importante es que el $60 \%$ de las concesiones Categoría 3 y 4; el 14,3\% de la Categoría 4 y 5 ; y el 12,5\% de la Categoría 3 han quedado con mala calificación medio ambiental. 


\section{Situación en Chile}
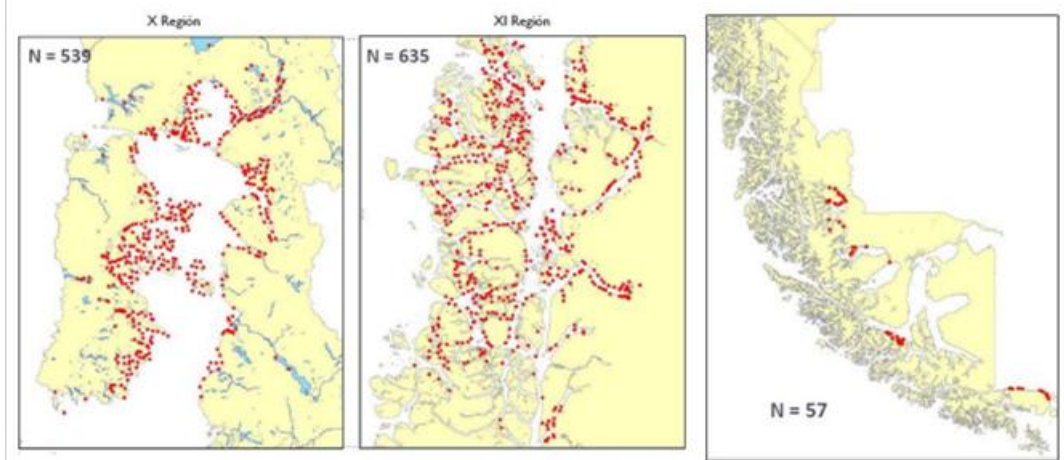

Figura 2. Concesiones por Región, tomado de la Propuesta para el Reglamento Densidades con Score de Riesgo y Plan de Manejo. Subsecretaria de Pesca y Acuicultura. Agosto del 2012.

Tabla 6. Registro de Concesiones entregado por distintas fuentes

\begin{tabular}{|c|c|c|c|c|c|}
\hline Año & X Región & XI Región & XII Región & Total & Fuente \\
\hline $\mathbf{2 0 0 8}$ & 474 & 526 & 41 & 1.041 & Cepal № 191 (Katz J. et al., 2011) \\
\hline $\mathbf{2 0 1 0}$ & 443 & 617 & Sin dato & 1.060 & Intrafish (2010) \\
\hline $\mathbf{2 0 1 1}$ & 539 & 635 & 57 & 1.231 & AquaBench (Garate O. 2011) \\
\hline $\mathbf{2 0 1 2}$ & 539 & 635 & 57 & 1.231 & Subpesca (2012) \\
\hline $\mathbf{2 0 1 3}$ & 562 & 395 & 21 & 978 & Sernapesca (2013) \\
\hline
\end{tabular}

Tabla 7. Concesiones de mar según informe Sernapesca, agosto 2013.

\begin{tabular}{|c|c|c|c|c|c|c|c|c|c|}
\hline & & & & & & & & Totales & $\%$ \\
\hline Regiones & 3 & 3 y 4 & 3 y 5 & 4 & 4 y 5 & 5 & No indicado & & \\
\hline Los lagos & 304 & 10 & 51 & 15 & 21 & 137 & 24 & 562 & 57,5 \\
\hline Aysén & 77 & 13 & 27 & 45 & 58 & 137 & 38 & 395 & 40,4 \\
\hline Magallanes & 10 & 0 & 4 & 0 & 1 & 6 & 0 & 21 & 2,1 \\
\hline Totales & 391 & 23 & 82 & 60 & 80 & 280 & 62 & 978 & 100 \\
\hline$\%$ & 40,0 & 2,4 & 8,4 & 6,1 & 8,2 & 28,6 & 6,3 & 100 & \\
\hline
\end{tabular}

En cambio vemos que la XI Región (Tabla 12) tiene un 23\% de las concesiones en condición de rechazo medio ambiental, y un $12,7 \%$ en la condición de Bitácoras ambientales y sanitarias. El 53,8\% de las concesiones Categoría 3 y 4; el 48,1\% de la Categoría 3 y 5; el 44,8\% de la Categoría 4 y 5; y el 36,4\% de la Categoría 3 están con mala calificación medio ambiental. 
Sustainability, Agri, Food and Environmental Reasearch 2(1): 1-35, 2013.

ISSN: 0719-3726

Finalmente al analizar los datos de la XII Región (Tabla 13), se aprecia que esta zona tiene un $23,8 \%$ de las concesiones en condición de rechazo medio ambiental, pero sin embargo, ninguna en Categoría de Bitácoras ambientales y sanitarias. Perdiendo la única concesión de la Categoría 4 y 5; el 30\% de la Categoría 3 y un 25\% de la Categoría 3 y 5 están con mala calificación medio ambiental.

Tabla 8. Categorías de las concesiones marítimas, lacustres y fluviales de Chile.

\begin{tabular}{|c|c|c|c|c|c|c|}
\hline Categoría & Tipo & Ambiente & Especies & $\begin{array}{l}\text { Prod. Máx. } \\
\text { (ton) }\end{array}$ & $\begin{array}{l}\text { Prof. Max } \\
\text { (m). }\end{array}$ & Fondo \\
\hline \multirow{3}{*}{0} & De fondo & Marino-Lacustre-Fluvial & Macroalgas & No indica & No indica & No indica \\
\hline & Extensivo & Marino-Lacustre-Fluvial & Todas excepto macroalgas. & $<1000$ & $>60$ & Duros o semiduros \\
\hline & Intensivo & Marino-Lacustre-Fluvial & Todas excepto macroalgas. & $<50$ & $>60$ & Duros o semiduros \\
\hline \multirow[t]{2}{*}{1} & Suspendido & Marino-Lacustre-Fluvial & Macroalgas & Sin limite & Sin limite & Cualquiera \\
\hline & Extensivo & Marino-Lacustre-Fluvial & Todas excepto macroalgas. & $<300$ & $>60$ & Blandos \\
\hline \multirow[t]{2}{*}{2} & Extensivo & Marino-Lacustre-Fluvial & Todas excepto macroalgas. & $300-1000$ & $>60$ & Blandos \\
\hline & Intensivo & Marino & Todas excepto macroalgas. & $<50$ & $>60$ & Blandos \\
\hline \multirow[t]{2}{*}{3} & Extensivo & Marino & Todas excepto macroalgas. & $>1000$ & $>60$ & Blandos \\
\hline & Intensivo & Marino & Todas & $>50$ & $>60$ & Blandos \\
\hline \multirow[t]{2}{*}{4} & Extensivo & Marino-Lacustre-Fluvial & Todas excepto macroalgas. & $>1000$ & $>60$ & Duros o semiduros \\
\hline & Intensivo & Marino-Lacustre-Fluvial & Todas & $>50$ & $>60$ & Duros o semiduros \\
\hline \multirow[t]{2}{*}{5} & Extensivo & Marino-Lacustre-Fluvial & Todas excepto macroalgas. & $>1000$ & $>60$ & No indica \\
\hline & Intensivo & Marino-Lacustre-Fluvial & Todas & $>50$ & $>60$ & No indica \\
\hline \multirow[t]{2}{*}{6} & Extensivo & Río-Desembocadura & Todas excepto macroalgas. & $>1000$ & $>60$ & Blandos \\
\hline & Intensivo & Río-Desembocadura & Todas & $>50$ & $>60$ & Blandos \\
\hline \multirow[t]{2}{*}{7} & Extensivo & Lagos-Lagunas & Todas excepto macroalgas. & $>1000$ & $>60$ & Blandos \\
\hline & Intensivo & Lagos-Lagunas & Todas & Sin limite & $>60$ & Blandos \\
\hline
\end{tabular}

Pero el hecho más significativo es el resultado que se produce (Figura 3), al comparar los porcentajes de centros con mala Calificación medio ambiental (anaeróbicos), con los años promedio de usos de los centros de las distintas regiones (línea azul); que para la X Región se estimó en 15 años; para la XI Región en 10 años; y para la XII Región en 5 años.

Se aprecia que la X Región es la zona que dispone de una mayor Capacidad de Carga, definida para la salmonicultura como la habilidad natural del ecosistema para usar y descomponer contaminantes potenciales sin efectos perjudiciales para el ambiente (Taller: Sustentabilidad y Manejo a Largo Plazo de la Actividad Acuícola, Puerto Montt, Enero 2010). En la X Región con un promedio estimado en 15 años de uso intensivo de las concesiones, solo se encuentra afectado ambientalmente el 9,6\% de ellas, en 
cambio en la XI Región con un uso estimado de 10 años, tiene afectada negativamente el $23 \%$ de las concesiones, pero más relevante es el hecho que en la XII, con un promedio de uso estimado en 5 años, ya va el $23,8 \%$ con mala calificación medio ambiental (Figura 3 ).

Tabla 9. Evaluación conceptual de la situación medio ambiental de las concesiones en Chile.

\begin{tabular}{|c|c|}
\hline Concepto & 'Descripción \\
\hline Aeróbico & Apto ambientalmente para su operación. \\
\hline Anaeróbico & No apto ambientalmente para su operación \\
\hline Bitácora & $\begin{array}{l}\text { Presentadas por pisciculturas, hatchery o centros de descanso a comienzos de cada } \\
\text { año hasta febrero. }\end{array}$ \\
\hline No corresponde evaluar & $\begin{array}{l}\text { Centros de cultivo que entregaron INFA sin tener la obligación de hacerlo (INFAS de } \\
\text { pre-operación antes que se cumpla un año sin operar y mitílidos cada un año por } \\
\text { ejemplo). }\end{array}$ \\
\hline $\begin{array}{l}\text { No evaluado por falta de } \\
\text { antecedentes. }\end{array}$ & $\begin{array}{l}\text { Centros de cultivo que entregaron INFA que no cumplieron con todos los aspectos } \\
\text { metodológicos indicados en la RE } 3612 \text { de } 2009 \text {, (falta de perfiles de la columna de } \\
\text { agua, falta de estaciones y muestreo posterior a la cosecha final, entre otros), por lo } \\
\text { que se emitió resolución del servicio prohibiendo el ingreso de nuevos ejemplares. }\end{array}$ \\
\hline
\end{tabular}

Tabla 10. Situación medio ambiental de las concesiones de mar de las regiones de los Lagos, Aysén y Magallanes, según informe Sernapesca, agosto 2013.

\begin{tabular}{|c|c|c|c|c|c|c|c|c|c|}
\hline & \multicolumn{7}{|c|}{ Categorías } & \multirow[t]{2}{*}{ Totales } & \multirow[t]{2}{*}{$\%$} \\
\hline & 3 & 3 y 4 & 3 y 5 & 4 & 4 y 5 & 5 & No indicado & & \\
\hline Aeróbicas & 297 & 10 & 60 & 43 & 48 & 264 & 0 & 722 & 73,8 \\
\hline Anaerobicas & 69 & 13 & 19 & 15 & 30 & 4 & 0 & 150 & 15,3 \\
\hline Bitácora & 6 & 0 & 0 & 1 & 1 & 9 & 62 & 79 & 8,1 \\
\hline No corresponde & 6 & 0 & 0 & 0 & 1 & 1 & 0 & 8 & 0,8 \\
\hline No evaluadas & 13 & 0 & 0 & 1 & 0 & 2 & 0 & 19 & 1,9 \\
\hline Totales & 391 & 23 & 3 & 60 & 80 & 280 & 62 & 978 & 100,0 \\
\hline$\%$ & 40,0 & 2,4 & 82 & 6,1 & 8,2 & 28,6 & 6,3 & 100,0 & \\
\hline
\end{tabular}

Finalmente, se debe tener en cuenta que desde que se iniciaron las fiscalizaciones en terreno de Sernapesca, además de la coordinación y asignación de las empresas medio ambientales que ejecutaran los muestreos, las concesiones con mala calificación medio ambiental han aumentado 8 veces desde Mayo del 2011 a Julio del 2013 (Figura 4). 
Sustainability, Agri, Food and Environmental Reasearch 2(1): 1-35, 2013.

Tabla 11. Situación medio ambiental de las concesiones de mar de la región de los lagos según informe Sernapesca, agosto 2013.

\begin{tabular}{|c|c|c|c|c|c|c|c|c|c|c|}
\hline & \multicolumn{7}{|c|}{ Categorías } & \multirow[t]{2}{*}{ Totales } & \multirow[t]{2}{*}{$\%$} & \multirow[t]{2}{*}{ Balance } \\
\hline & 3 & 3 y 4 & 3 y 5 & 4 & 4 y 5 & 5 & No indicado & & & \\
\hline Aeróbicas & 249 & 4 & 46 & 13 & 17 & 130 & 0 & 459 & \multicolumn{2}{|c|}{81,7} \\
\hline Anaerobicas & 38 & 6 & 5 & 1 & 3 & 1 & 0 & 54 & \multicolumn{2}{|r|}{9,6} \\
\hline Bitácora & 1 & 0 & 0 & 0 & 0 & 4 & 24 & 29 & 5,2 & \multirow{3}{*}{8,7} \\
\hline No corresponde & 3 & 0 & 0 & 0 & 1 & 1 & 0 & 5 & 0,9 & \\
\hline No evaluadas & 13 & 0 & 0 & 1 & 0 & 1 & 0 & 15 & 2,7 & \\
\hline Totales & 304 & 10 & 51 & 15 & 21 & 137 & 24 & 562 & 100 & 100 \\
\hline$\%$ del total & 54,1 & 1,8 & 9,1 & 2,7 & 3,7 & 24,4 & 4,3 & 100,0 & & \\
\hline Base $100 \%$ & 304 & 10 & 51 & 15 & 21 & 137 & 24 & 562 & & \\
\hline$\%$ Anaerobicas & 12,5 & 60,0 & 9,8 & 6,7 & 14,3 & 0,7 & 0,0 & 9,6 & & \\
\hline$\%$ No utilizables & 5,6 & 0,0 & 0,0 & 6,7 & 4,8 & 4,4 & 100,0 & 8,7 & & \\
\hline $\begin{array}{l}\% \text { Anaeróbicas }+ \text { no } \\
\text { utilizables }\end{array}$ & 18,1 & 60,0 & 9,8 & 13,4 & 19,1 & 5,1 & 100,0 & 18,3 & & \\
\hline \% Disponible & 81,9 & 40,0 & 90,2 & 86,6 & 80,9 & 94,9 & 0,0 & 81,7 & & \\
\hline
\end{tabular}

Tabla 12. Situación medio ambiental de las concesiones de mar de la región de Aysén según informe Sernapesca, agosto 2013.

\begin{tabular}{|c|c|c|c|c|c|c|c|c|c|c|}
\hline & \multicolumn{7}{|c|}{ Categorías } & \multirow[t]{2}{*}{ Totales } & \multirow[t]{2}{*}{$\%$} & \multirow[t]{2}{*}{ Balance } \\
\hline & 3 & 3 y 4 & 3 y 5 & 4 & 4 y 5 & 5 & No indicado & & & \\
\hline Aeróbicas & 41 & 6 & 12 & 30 & 31 & 128 & 0 & 248 & \multicolumn{2}{|r|}{62,8} \\
\hline Anaerobicas & 28 & 7 & 13 & 14 & 26 & 3 & 0 & 91 & \multicolumn{2}{|r|}{23,0} \\
\hline Bitácora & 5 & 0 & 0 & 1 & 1 & 5 & 38 & 50 & 12,7 & \multirow{3}{*}{14,2} \\
\hline No corresponde & 3 & 0 & 0 & 0 & 0 & 0 & 0 & 3 & 0,8 & \\
\hline No evaluadas & 0 & 0 & 2 & 0 & 0 & 1 & 0 & 3 & 0,8 & \\
\hline Totales & 77 & 13 & 27 & 45 & 58 & 137 & 38 & 395 & 100 & 100 \\
\hline$\%$ del total & 19,5 & 3,3 & 6,8 & 11,4 & 14,7 & 34,7 & 395 & 100 & & \\
\hline Base $100 \%$ & 77 & 13 & 27 & 45 & 58 & 137 & 9,6 & 395 & & \\
\hline \% Anaerobicas & 36,4 & 53,8 & 48,1 & 31,1 & 44,8 & 2,2 & 0,0 & 23,0 & & \\
\hline$\%$ No utilizables & 10,4 & 0,0 & 7,4 & 2,2 & 1,7 & 4,4 & 100,0 & 14,2 & & \\
\hline $\begin{array}{l}\% \text { Anaeróbicas + no } \\
\text { utilizables }\end{array}$ & 46,8 & 53,8 & 55,5 & 33,3 & 46,5 & 6,6 & 100,0 & 37,2 & & \\
\hline \% Disponible & 53,2 & 46,2 & 44,5 & 66,7 & 53,5 & 93,4 & 0,0 & 62,8 & & \\
\hline
\end{tabular}


Sustainability, Agri, Food and Environmental Reasearch 2(1): 1-35, 2013.

Tabla 13. Situación medio ambiental de las concesiones de mar de la región de Magallanes según informe Sernapesca, agosto 2013.

\begin{tabular}{|c|c|c|c|c|c|c|c|c|c|c|}
\hline & \multicolumn{7}{|c|}{ Categorías } & \multirow[t]{2}{*}{ Totales } & \multirow[t]{2}{*}{$\%$} & \multirow[t]{2}{*}{ Balance } \\
\hline & 3 & 3 y 4 & 3 y 5 & 4 & 4 y 5 & 5 & No indicado & & & \\
\hline Aeróbicas & 7 & 0 & 2 & 0 & 0 & 6 & 0 & 15 & \multicolumn{2}{|r|}{71,4} \\
\hline Anaerobicas & 3 & 0 & 1 & 0 & 1 & 0 & 0 & 5 & \multicolumn{2}{|r|}{23,8} \\
\hline Bitácora & 0 & 0 & 0 & 0 & 0 & 0 & 0 & 0 & 0,0 & \multirow{3}{*}{4,8} \\
\hline No corresponde & 0 & 0 & 0 & 0 & 0 & 0 & 0 & 0 & 0,0 & \\
\hline No evaluadas & 0 & 0 & 1 & 0 & 0 & 0 & 0 & 1 & 4,8 & \\
\hline Totales & 10 & 0 & 4 & 0 & 0 & 0 & 0 & 21 & 100 & 100 \\
\hline$\%$ del total & 47,6 & 0,0 & 19,0 & 0 & 4,8 & 28,6 & 0,0 & 100 & & \\
\hline Base $100 \%$ & 10 & 0 & 4 & 0 & 1 & 6 & 0 & 21 & & \\
\hline$\%$ Anaerobicas & 30,0 & 0,0 & 25,0 & 0,0 & 100,0 & 0,0 & 0,0 & 23,8 & & \\
\hline$\%$ No utilizables & 0,0 & 0,0 & 25,0 & 0,0 & 0,0 & 0,0 & 0,0 & 4,8 & & \\
\hline $\begin{array}{l}\% \text { Anaeróbicas + } \\
\text { no utilizables }\end{array}$ & 30,0 & 0,0 & 50,0 & 0,0 & 100,0 & 0,0 & 0,0 & 28,6 & & \\
\hline \% Disponible & 70,0 & 0,0 & 50,0 & 0,0 & 0,0 & 100,0 & 0,0 & 71,4 & & \\
\hline
\end{tabular}

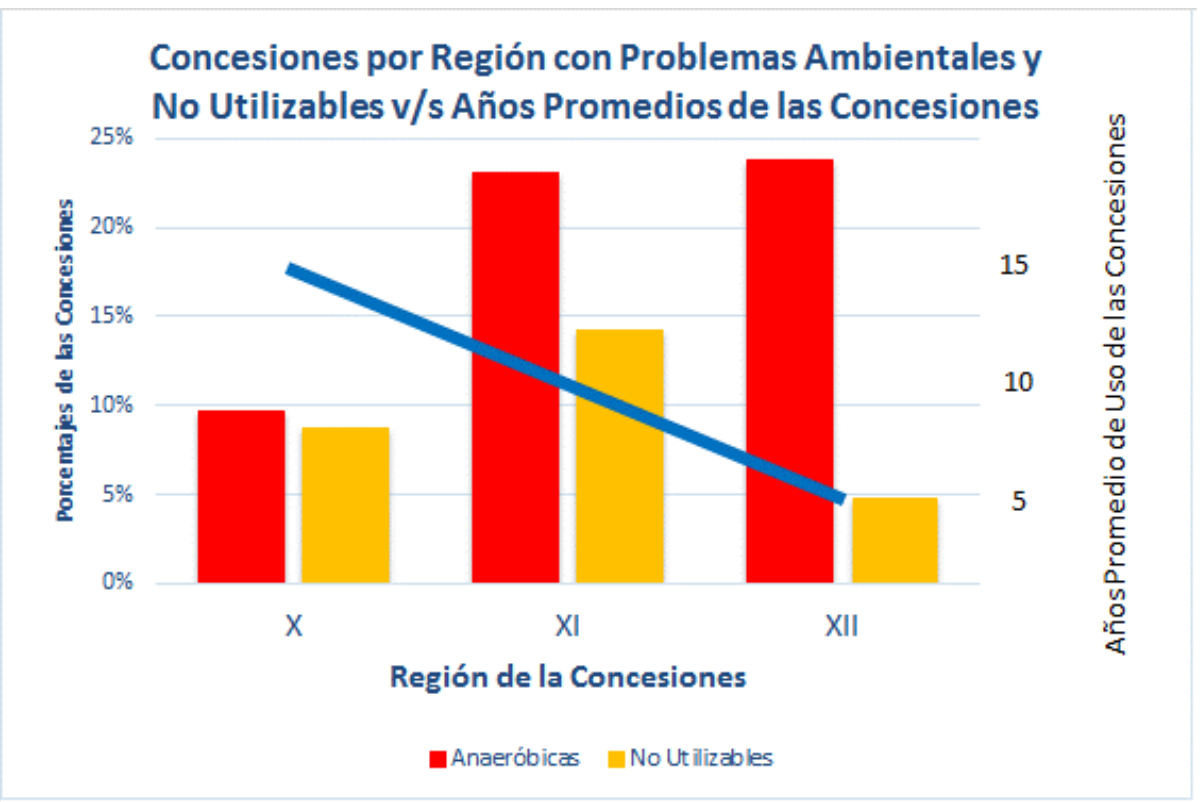

Figura 3. Concesiones con problemas ambientales en Chile. 


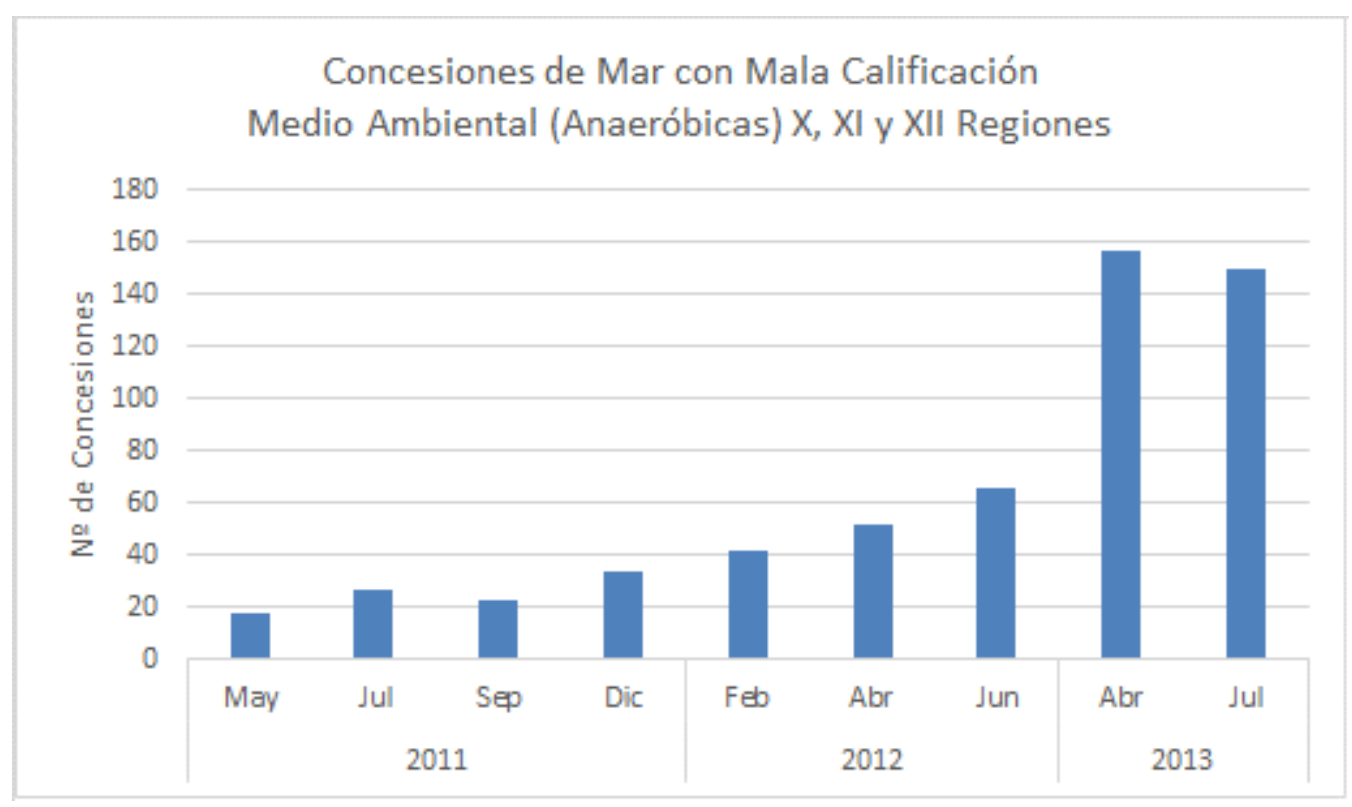

Figura 4. Concesiones de Mar con Mala Calificación Medio Ambiental en Chile.

Respecto a las concesiones Anaeróbicas (con ambiente sedimentario desprovisto de oxígeno), Jarpa et al. (2007) citando a Pantoja et al. (2004) indica que normalmente los ambientes acuáticos tienen la capacidad de metabolizar los residuos orgánicos mediante la acción de poblaciones bacterianas, que habitan tanto en la columna de agua como en los sedimentos marinos, siendo estas colonias las encargadas del reciclamiento de nutrientes ( $\mathrm{N}$ y P) en el mar.

Uribe (2012) señala que "desde el punto de vista técnico-ecológico estas condiciones anaeróbicas son causadas por la sobrecarga de materia orgánica que ocurre bajo los cultivos de salmónidos por enriquecimiento orgánico proveniente de la sedimentación de alimento no consumido y heces de salmónidos. Parte de este material al entrar en contacto con el agua es ingerido por organismos zooplanctónicos. No obstante, debido a la densidad de estos componentes ellos sedimentan rápidamente con velocidades cercanas a 0,03 m s-1 para heces (Gowen \& Bradbury, 1987) y entre 0,05 y 0,16 m s-1 para el alimento (Cromey et al. 2002a). Ya en el bentos, es una fuente potencial de energía para organismos bentónicos y para bacterias aeróbicas heterótrofas, lo que genera una alta demanda biológica de oxígeno (Lenihan \& Micheli, 2001). La demanda puede agotar el oxígeno disponible si el suministro de materia orgánica es muy alto. Si ello ocurre el oxígeno es agotado y aceptores de electrones alternativos tales como nitritos, nitratos, dióxido de carbono y sulfatos son utilizados por 
bacterias anaeróbicas en la descomposición de la materia orgánica remanente (Bagarinao, 1992) liberándose amonio, sulfuros, metano y otros iones o moléculas reducidas de alta toxicidad para los organismos que allí habitan (Weston, 1990; Wu \& Lam, 1994; Vita et al., 2002). Para los organismos que habitan estos sedimentos (megafauna ( $>2 \mathrm{~mm}$ ), macrofauna $(2-0,5 \mathrm{~mm}$ ) y meiofauna $(0,5-0,047 \mathrm{~mm})$ esta condición les genera una disminución de sus curvas de abundancia, biomasa y riqueza de especies (Pearson \& Rosenberg, 1978) y una dominancia de especies oportunistas pertenecientes a la epifauna (Kutti et al. 2007)".

Para Buschmann \& Fortt (2005) la industria salmonera nacional ha generando distintos problemas de polución: disminución de la biodiversidad alrededor de las jaulas; exceso de utilización de antibióticos en salmones; y la posible relación de la descarga orgánica de las balsas con la eutroficación y la generación de floraciones algales; a lo que se debe agregar las condiciones anaeróbicas que se produce en el sedimento.

\section{Alternativas de Recuperación para Concesiones Anaeróbicas}

En relación al tiempo de recuperación (natural) de un sitio Black, Hansen \& Holmer (2008), establecen que en la escala de los procesos de recuperación, ciertamente hay diferencias dependiendo del sitio, la región y el grado de impacto inicial, pero parece claro que la recuperación química significativa se produce con relativa rapidez, donde el carbono orgánico lábil se degrada en unos pocos meses. La recuperación biológica puede llevar años, dependiendo del sitio, pero no parece haber razón para exigir la recuperación total, dado que el bentos se verá afectado tan pronto como el próximo ciclo acuícola se reanude. Black et al. (2008) señalan que en Canadá probablemente los trabajos de Brooks, Stierns \& Backman, (2004) y Brooks et al. (2003) son la serie más completa de estudios de recuperación (natural) en sitios salmoneros, y se han observado en ellos una amplia gama de tasas de recuperación (natural), que van de unas pocas semanas hasta más de 6 años.

Para los mismos autores no existe un solo indicador tipo "bala mágica". Más bien es un conjunto de indicadores, los que debe ser evaluado con el fin de interpretar correctamente el estado de los sedimentos: si un conjunto de indicadores inapropiados son elegido, entonces es muy posible llegar a conclusiones engañosas (Mulsow et al. 2006). Sin embargo, existen determinados modelos que se ajustan bien a lo que tratan de definir, por ejemplo el modelo de Pearson-Rosenberg (1978), que es el modelo que mejor predice el estado ambiental de un centro Categoría 3.

Los sedimentos con granos medianos y finos (e.g. no fangoso), albergan una gran cantidad de individuos debido a la alta complejidad estructural que proporcionan los numerosos espacios disponibles. Cuanto 
más complejo sea estructuralmente el sedimento ofrecerá un mayor número de nichos, hábitat estructuralmente más complejo y un aumento en la diversidad (Silva \& Quiroga, 2010).

En forma más general, se ha determinado que en los ambientes sedimentarios la Capacidad de Carga se encuentra más bien relacionada con:

a) El nivel de desarrollo que el ensamble ecológico tenga en su fauna bentónica, que le permita una cierta capacidad para metabolizar los desechos orgánicos.

b) La capacidad Biogeoquímica de los microorganismos (bacterias) para degradar los elementos a su condición de nutrientes.

c) La forma en que estas comunidades de organismos (fauna bentónica y bacterias) son capaces de albergarse en el sedimento, lo que está determinado por la tasa de acumulación y composición de partículas orgánicas en el fondo, que a su vez depende del tamaño, densidad y composición granulométrica.

d) La cantidad de oxígeno disuelto disponible que se encuentre en la interfase agua-sedimento o en el agua suprayacente al fondo.

e) El patrón de corrientes de las inmediaciones, que determina la dispersión de desechos orgánicos sólidos y define el grosor y extensión de la capa de materia orgánica que el bentos debe metabolizar.

Sin embargo, varios autores indican que para los centros de cultivo de salmón, podrían ser controlados su condición medio ambiental mediante un estudio de la macrofauna bentónica. Siendo probablemente en esta línea el AMBI (Borja et al. 2000), el mecanismo predictor más promisorio para la comunidad científica, y que corresponde a una clasificación de las especies bentónicas en grupos ecológicos, basado en la sensibilidad o tolerancia de la infauna a la contaminación o enriquecimiento orgánico de acuerdo a los criterios que se detallan en la Tabla 14 (Stead \& Uribe, 2012).

Como se ha indicado Uribe (2012), señala que entre los factores que están asociados a que algunos sitios superen la Capacidad de Carga orgánica y otros no, y por ende algunos presenten condiciones anaeróbicas y otros no, se encuentran aquellos relacionados a la operatividad del centro de cultivo y aquellos relacionados a la hidrodinámica del sector.

Por lo cual, las posibles alternativas de recuperación medio ambiental para concesiones Anaeróbicas son cuatro:

1. Dejar descansar el sitio hasta el restablecimiento de condiciones medio ambientales favorables. Lo que puede bastar los 3 meses de descanso natural que se permite en un Barrio, o pasar hasta 
el próximo ciclo de 24 meses o más ciclos, dependiendo de las condiciones de recuperación propias del centro.

2. Mover los módulos de cultivo de posición dentro de la misma concesión. Lo que por normativa medio ambiental se mantienen los monitoreos ambientales (INFAs) en los puntos originales de módulo, por lo tanto, el tiempo necesario para su recuperación también dependerá de las condiciones de recuperación propias del área en que se ubicaba originalmente el módulo reubicado.

3. Utilizar otra concesión para el cultivo. Lo que implica que al usar otra concesión propia, la con mala Calificación medio ambiental queda en descanso, por lo menos un ciclo completo (24 meses), utilizando en la práctica 2 concesiones; o tener que arrendar otra concesión, si no se dispone de otra propia.

4. Utilizar el Artículo 8o bis de la modificación del RAMA (D.S. № 86 de 2007 Publicado Diario Oficial del 08 Enero 2008), que permite "el uso de mecanismos físicos, productos químicos y biológicos, - la realización de cualquier proceso que modifique las condiciones de oxígeno del área de sedimentación, así como las actividades que resuspendan el sustrato, el arado, arrastre, aspirado o extracción del material sedimentado proveniente de centros de cultivo, sólo podrán ser llevado a cabo previa autorización por resolución fundada de la Subsecretaría". Actualmente en Chile existe la tecnología y la experiencia para utilizar esta normativa. Que corresponde a la técnica, que admite mantener en condiciones aeróbicas en el sedimento del centro, o recuperar esta condición en el periodo de descanso que dispone un Barrio (3 meses).

Una Propuesta Sustentable para el Mantenimiento Medio Ambiental de las Concesiones

Con los antecedentes presentados, se puede deducir que si bien esta industria, como todas las actividades productivas, o como cualquier tipo de intervención que se realiza en el medio ambiente directa o indirectamente, provocada por un proyecto o actividad produce alteraciones en el medio (Forter, 2001) genera contaminación. Pero estas por las evidencias presentadas después de 30 años de operación de la actividad salmonera nacional, no son del grado extremo que algunos indican, y que sustentado en ese argumento plantean la completa inviabilidad de esta actividad. Sin embargo, tampoco la contaminación que se produce es de un nivel bajo, que le permita a la industria no reconocerlas y enfrentar abiertamente el problema, sobre todo cuando se tiene un importante grado de consenso de cuáles son las principales: 
1. Las condiciones anaeróbicas que se produce en el sedimento, que se cuantifica y determina en las mediciones INFAs. Que es la forma definitiva en que la Autoridad determina si la concesión está apta o no para su operación.

2. Disminución de la biodiversidad alrededor de las jaulas, que es cuantificable y que también son determinadas en las mediciones INFAs.

3. Exceso de utilización de antibióticos en el manejo sanitario de los salmones, que está siendo cada vez más controlada por la normativa sanitaria.

4. La posible relación de la descarga orgánica de las balsas con la eutroficación y estas con la generación de floraciones algales. Que aún es más bien una hipótesis, que debe ser demostrada.

De estas cuatro principales, las dos primeras son revertidas con la aplicación de una de las 4 alternativas de recuperación para concesiones Anaeróbicas, que se indicaron en el apartado anterior. Lo que permite desvirtuar la creencia que la contaminación medio ambiental del fondo marino es casi irreversible, sino más bien refuerza el hecho que solo es un problema de tiempo, lo que su vez dependerá de las características dinámicas particulares (batimetría, correntometría, ubicación geográfica, por mencionar algunas), que tenga la concesión a recuperarse ambientalmente. Incluso siendo los propios ambientalistas los que indican, que el tiempo estimado que para tener una recuperación de la comunidad bentónica se necesitaría de 5 o 6 años (García, 2005).

Para el tercer aspecto, como se ha indicado, la normativa sanitaria en general está orientada a disminuir fuertemente su utilización, y otro lado toda la industria está empeñada a disminuir los riesgos biosanitarios. Con respecto al cuarto punto, este aún se encuentra en evaluación, sin embargo como se indicó, los ambientes acuáticos tienen la capacidad de metabolizar los residuos orgánicos mediante la acción de poblaciones bacterianas que habitan tanto en la columna de agua como en los sedimentos marinos (Pantoja et al. 2004).

Sin embargo, hay un aspecto que se debe tener en consideración, tanto por las empresas salmoneras como por los organismos reguladores, y tiene relación con los resultados que se muestran en la Tabla № 15. En ella se indica que el $56,5 \%$ de las concesiones Categoría 3 y 4 ; el 37,5\% de las Categoría 4 y 5 ; el 25\% de la Categoría 4; y el 23,2\% de la Categoría 3 y 5 se encuentran con una Calificación Anaeróbica, pero lo más significativo es que en todas estas Categorías, la mayor cantidad de concesiones con negativa Calificación medio ambiental se encuentran ubicadas en la XI Región.

Solo se diferencian las concesiones de Categoría 3, donde el mayor número de Calificaciones Anaeróbicas se encuentran en la X Región (38 concesiones), pero lo relevante también es el hecho que en la X Región las concesiones Categoría 3 son 304 y de ellas 38 son Anaeróbicas lo que representan el 
Sustainability, Agri, Food and Environmental Reasearch 2(1): 1-35, 2013.

12,5\%; sin embargo en la XI Región las concesiones Categoría 3 son 77 y de ellas 28 están Anaeróbicas, lo que representan el 36,4\% (Tabla 15).

Tabla 14. Valores del coeficiente biótico $A M B I$ y su equivalencia el índice biótico y con el estado de las comunidades bentónicas y el nivel de perturbación de los sedimentos (Fuente: Borja et al. 2000; Muxica et al. 2005). Tomado de Stead \& Uribe (2012).

\begin{tabular}{|c|c|c|c|c|c|}
\hline Rango de valores $\mathrm{AMBI}$ & Índice biótico & $\begin{array}{l}\text { Grupo ecológico } \\
\text { dominante }\end{array}$ & $\begin{array}{l}\text { Estado de comunidad } \\
\text { bentónica }\end{array}$ & Nivel de perturbación & $\begin{array}{l}\text { Estatus } \\
\text { ecológico }\end{array}$ \\
\hline $0,0<\mathrm{AMBI} \leq 0,2$ & 0 & 1 & Normal & \multirow[t]{2}{*}{ No perturbada } & \multirow[t]{2}{*}{ Alto } \\
\hline $0,2<\mathrm{AMBI} \leq 1,2$ & 1 & II & Empobrecida & & \\
\hline $1,2<\mathrm{AMBI} \leq 3,3$ & 2 & III & Desbalanceada & Levemente perturbada & Bueno \\
\hline $3,3<\mathrm{AMBI} \leq 4,3$ & 3 & \multirow[t]{2}{*}{ IV - V } & Poco contaminada & \multirow[t]{2}{*}{ Moderadamente perturbada } & Moderado \\
\hline $4,3<\mathrm{AMBI} \leq 5,0$ & 4 & & Contaminada & & \multirow[t]{2}{*}{ Pobre } \\
\hline $5,0<\mathrm{AMBI} \leq 5,5$ & 5 & \multirow[t]{2}{*}{ V } & $\begin{array}{l}\text { Altamente } \\
\text { contaminada }\end{array}$ & \multirow[t]{2}{*}{ Altamente perturbada } & \\
\hline $5,5<\mathrm{AMBI} \leq 6,0$ & 6 & & $\begin{array}{l}\text { Extremadamente } \\
\text { contaminada }\end{array}$ & & \multirow[t]{2}{*}{ Malo } \\
\hline Azoico 7 & 7 & Azoico & & Extremadamente perturbada & \\
\hline
\end{tabular}

Tabla 15. Situación medio ambiental de las concesiones de mar de las regiones de Los lagos, Aysén y Magallanes, según informe Sernapesca, agoto 2013.

\begin{tabular}{|c|c|c|c|c|c|c|c|c|c|c|}
\hline & & \multicolumn{7}{|c|}{ Categorías } & \multirow[t]{2}{*}{ Totales } & \multirow[t]{2}{*}{$\%$} \\
\hline & & 3 & 3 y 4 & 3 y 5 & 4 & 4 y 5 & 5 & No indicado & & \\
\hline \multirow{6}{*}{$\begin{array}{l}\text { Concesiones } \\
\text { según calificación } \\
\text { medio ambiental }\end{array}$} & Aeróbicas & 10 & 48 & 43 & 60 & 297 & 264 & 0 & 722 & 73,8 \\
\hline & Anaerobicas & 13 & 30 & 15 & 19 & 69 & 4 & 0 & 150 & 15,3 \\
\hline & Bitácora & 0 & 1 & 1 & 0 & 6 & 9 & 62 & 79 & 8,1 \\
\hline & No corresponde & 0 & 1 & 0 & 0 & 6 & 1 & 0 & 8 & 0,8 \\
\hline & No evaluadas & 0 & 0 & 1 & 3 & 13 & 2 & 0 & 19 & 1,9 \\
\hline & Totales & 23 & 80 & 60 & 82 & 391 & 280 & 62 & 978 & 100 \\
\hline \multirow{5}{*}{$\begin{array}{l}\text { Concesiones } \\
\text { anaeróbicas por } \\
\text { región }\end{array}$} & Los Lagos & 6 & 3 & 1 & 5 & 38 & 1 & 0 & 54 & 9,6 \\
\hline & Aysén & 7 & 26 & 14 & 13 & 28 & 3 & 0 & 91 & 23,0 \\
\hline & Magallanes & 0 & 1 & 0 & 1 & 3 & 0 & 0 & 5 & 23,8 \\
\hline & Totales & 13 & 30 & 15 & 19 & 69 & 4 & 0 & 150 & 15,3 \\
\hline & $\%$ & 56,5 & 37,5 & 25,0 & 23,2 & 17,6 & 1,4 & 0,0 & 15,3 & \\
\hline
\end{tabular}


Situación medio ambiental de las concesiones que indicaría que la XI Región se encuentra en un grado superior de contaminación que las concesiones de la X Región, que en 15 años estimado de uso tienen un 9,6\% de las concesiones Anaeróbicas, versus la XI Región que con 10 años estimado de uso con sus concesiones, van en $23 \%$ de sus concesiones en condiciones Anaeróbicas. Lo que alguna forma se podría explicar con el hecho que las diferencias de mareas en la XI Región son de menor amplitud que en la X Región, lo que podría significar una menor tasa de recambio de agua en la XI con respecto a la X. Otra diferencia podría estar radicada que las concesiones de la XI ubicadas en los fiordos, tienen una alta sedimentación natural, y como se ha indicado, una baja tasa de renovación de agua, lo que al ser cargada con una producción acuícola, hace que rápidamente la materia orgánica sedimente y que no se degrade a la velocidad que lo permiten las concesiones de la X Región.

Es muy posible que la mejor solución para las concesiones con mala Calificación medio ambiental de la XI Región, sea la reubicaciones de concesiones que se encuentran ubicadas en los fiordos interiores de la XI Región, para que estas puedan ser reubicadas en las zonas exteriores y más expuestas de la XI Región. Lo que podría significar además un cambio conceptual, operacional y productivo, para poder operar en las zonas más expuestas de la XI Región, donde se van a requerir jaulas más fuertes, fondeos más resistentes y una mayor capacidad logística para producir, lo que indudablemente también repercutirá en un aumento de los costos.

A juzgar por los resultados del 23,8\% de las concesiones con Calificación Anaeróbica en la XII Región, es muy probable que sea una situación similar o inclusive más acentuada a lo que sucede en la zona interior de los fiordos de la XI Región. Una buena forma de evaluar preliminarmente esta hipótesis es revisando la Caracterización Preliminar de Sitios (CPS) en la XII Región, y verificar si el material sedimentario natural granulométricamente están o son más fino, que el existente en las zonas interiores de los fiordos de la XI Región.

Por lo tanto, estos antecedentes nos llevan a proponer que las concesiones que deben ser prioritaria y especialmente cuidadas y mantenidas en buenas condiciones ambientales, son las ubicadas en la $\mathrm{X}$ Región. Adoptando en esta Región protocolos preventivos que permitan mantener las concesiones siempre con Calificación Aeróbica, alejándose lo más posibles sus parámetros INFAs de una situación medio ambiental negativa, que limita las posibilidades de recuperación de las condiciones ambientales naturales de la concesión. Recuperar productivamente concesiones en el estuario Reloncaví, el Golfo de Ancud, Chiloé Insular y Continental, son probablemente de un valor superior a cualquiera de las concesiones de la XI Región, si logra igualdad de condiciones biosanitarias en ambas regiones, dado que los costos operacionales serán siempre menores a los centros más alejados. 
La propuesta Sustentable para el mantenimiento medio ambiental de las concesiones en corto y mediano plazo, consiste en mantener siempre todas la concesiones en la X, XI y XII Regiones con Calificación Aeróbica, se utilicen o no productivamente. Esta sería la mejor y más clara demostración de las empresas salmoneras, que se encuentran con un real compromiso en la Sustentabilidad de actividad, haciéndose cargo de la contaminación como su mayor externalidad que la actividad produce; y los organismos fiscalizadores podrían dar fe de aquello con toda la transparencia que las ONGs y centros de estudios sociales y universitarios, manifiestan no existir en esta industria.

\section{Oportunidad para la Industria}

Saavedra (2010) señala: para que esta industria sea realmente Sustentable debe cumplir una serie de parámetros, que hoy se pueden resumir en la aplicación de la norma ISO 14.001 y el programa especialmente diseñado en la industria salmonera denominado SIGES, ante las cuales las empresas salmoneras que las han implantado (> 60\%) han demostrado competencia y eficiencia en su cumplimiento. El mismo autor con respecto a la RSE, indica que el apoyo económico a escuelas locales, o a proyectos de infraestructura comunal, o a iniciativas culturales, o deportivas locales, permiten inferir que los sistemas de gestión ambiental actualmente operativos en empresas del sector salmonicultor, si bien es cierto, responden eficazmente a las exigencias formales impuestas por los modelos de normas de gestión ambiental de donde provienen; pero al mismo tiempo, no estarían siendo considerados por las empresas (paradójicamente), como instrumentos susceptibles de ser transformados en focos de promoción de acciones, orientadas hacia el desarrollo Sustentable de las comunidades donde están insertas sus operaciones.

La reciente crisis sanitaria por el virus ISA, por la que ha debido pasar la industria nacional ha tenido implicancias significativas sobre las tres componentes que configuran el concepto de desarrollo Sustentable (ambiental-económico-social); afectando y cuestionando seriamente el modelo de desarrollo imperante. Ratificando la necesidad de revisar los modelos de gestión general que se aplican al interior de las empresas salmoneras, cuya aplicación ha estado orientada fundamentalmente a Producción, descuidando otros elementos casi tan relevantes como los aspectos económicos asociados a la cadena de valor del proceso productivo, como los son los aspectos ambientales, de bioseguridad y sociales.

Por otra parte, Werner K. (com. pers.) indica que a nivel de industria existe hoy el convencimiento que el modelo productivo diseñado post ISA, debe ser revisado y reformulado. Porque los costos entre US\$ 5 y 5,5/kg de Salmon o Trucha promedio exportado, no están dando margen. Dado los actuales precios de 
venta, que no son bajos, con suerte a las empresas les permiten estar en equilibrio con su costo, y a otras más eficientes rentar un bajo margen. Lejos de lo que actualmente logran los noruegos, que están con costos productivos más bajos que los chilenos.

Para la industria salmonera desde sus inicios el apoyo del Estado y sus organismos relacionados con la actividad, han tenido una acción preponderante, que además a lo largo de su historia les ha permitido su desarrollo: tales como el Estatuto de la Inversión Extranjera o Decreto Ley 600, que puso a la inversión extranjera en el esquema de desarrollo implementado en Chile; además en el caso de la salmonicultura la Ley Austral № 19.606, que beneficia a las inversiones realizadas en las XI y XII regiones y en la provincia de Palena; la Ley Navarino № 18.392, que beneficia a las empresas que desarrollan actividades productivas que se instalen en la XII Región, a través de exenciones tributarias (Gutiérrez, 2005). Ayudando también a superar varias crisis importantes: acusación de damping por parte de los productores norteamericanos (1997-1999), crisis de precios en los mercados asiáticos (1998) y virus ISA (2008 - 2010). Sin embargo, sobre un tema las empresas salmoneras si tienen un consenso: es que es muy poco probable que el Estado intervenga, para resolver los problemas estructurales del sector. Por tanto, deberán ser sus propios protagonistas los que deban tomar una actitud proactiva para solucionar los problemas estructurales indicados.

Tomando las palabras de los empresarios que indican que son ellos: los que asumen los riesgos patrimoniales y forjan las expectativas de la gente que trabaja en el sector. Es pertinente plantearles en este sentido, que continuar en una posición de prudente silencio, que varias veces pudo haber sido considerado como una buena respuesta para sus detractores, dados los últimos acontecimientos, esta industria debe replantearse en la búsqueda de una formula, que le permita rápidamente proyectarse definitivamente en el largo plazo, y tener que afianzar sus características de una actividad verdaderamente Sustentable, con un cluster bien estructurado y consolidado. Y que para lograr este objetivo, deberán pasar de una posición medio ambiental, que hasta ahora ha sido siempre reactiva a una proactiva, que les permita cuidar el mayor patrimonio que disponen las empresas salmoneras: sus concesiones.

\section{Bibliografía}

Alvial A. 2002. Desarrollo y Perspectiva de la Industria Salmonera. Presentación INTESAL de SalmonChile en power point 42 láminas.

Bañados F. y A. Alvial. 2007. Desafíos en la Consolidación del Cluster del Salmón Chileno: Contribución del Programa Territorial Integrado (PTI). INTESAL de SalmonChile. Salmo Ciencia 11 pp. 
Black, K.D., Hansen, P.K. y M. Holmer. 2008. Salmon Aquiculture Dialogue: Working Group Report on Benthic Impacts and Farm Siting. 54 p.

Buschmann, A. 2001. Impacto ambiental de la acuicultura. El estado de la investigación en Chile y el mundo. Terram Publicaciones. 67 pp.

Buschmann, A. y A. Fortt. 2005. Industria y Contaminación Marina. Documento 19 Oceana. 38 p.

Buschmann, A. 2005 Marea roja y salmonicultura en el sur de Chile. Documento 14 Oceana 14 pp.

Bustos, B. 2012. Brote del virus ISA: Crisis ambiental y capacidad de la institucionalidad ambiental para manejar el conflicto. EURE Vol. 38, N 115, Septiembre 2012. pp 219-245.

Brooks, K. 2001. An evaluation of the relationship between salmon farm biomass, organic inputs to sediments, physicochemical changes associated with those inputs and infaunal response - with emphasis on total sediment sulfides, total volatile solids, and oxidation-reduction potential as surrogate endpoints for biological monitoring. Aquatic Environmental Sciences. Port Townsend. Washington. USA. 172 pp.

Castillo, M. y C. Valenzuela. 2006. Avances en el conocimiento oceanográfico de las aguas interiores chilenas. Comité Oceanográfico Nacional - Pontificia Universidad Católica de Valparaíso, Valparaíso pp. $59-62$.

Claude M., J. Oporto, C. Ibáñez, L. Brieva, C. Espinosa, y M. Arqueros. 2000. La ineficiencia de la Salmonicultura en Chile: Aspectos sociales, económicos y ambientales. Fundación Terram. 72 pp.

Dorem D. y J. Gabella. 2001. Salmonicultura en Chile: Desarrollo, proyecciones e impacto. Terram Publicaciones. 39 pp.

Fierro J., 2006. Avances en el conocimiento oceanográfico de las aguas interiores chilenas. Comité Oceanográfico Nacional - Pontificia Universidad Católica de Valparaíso, Valparaíso pp. 63-66.

García, F. 2005. Salmones en Chile. El negocio de comerse el mar. Documento 4. Veterinario Sin Fronteras. Fundación Kontrast. 34 pp.

Gutiérrez, C. 2005. Moratoria a la salmonicultura. Documento 15. Oceana. 19 pp.

Jarpa, M., A. Aguilar, M. Belmonte, J. Decap, M. Abarzúa y G. Vidal 2007. Determinación de la capacidad nitrificante de un sedimento marino proveniente de un centro de cultivo de salmones. Interciencia, 32 : 679-685.

Katz J., M. lizuka y S. Muñoz. 2011. Creciendo en base a los recursos naturales, "tragedias de los comunes" y el futuro de la industria salmonera chilena. CEPAL División de Desarrollo Productivo y Empresarial Serie № 191 Chile. 95 pp 
Pineda V., 2006. Granulometría y Geoquímica de los Sedimentos Marinos en el área comprendida entre el Seno Reloncaví y Golfo Corcovado, Chile. Crucero CIMAR 10 Fiordos. Ciencia y Tecnología del Mar. 32 $\mathrm{N}^{\circ} 1,2009$ pp. $27-47$.

Rehbein, N. 2011. Propuesta de metodología para la estimación del impacto económico de la contaminación del fondo marino por la emisión de alimento y heces de la salmonicultura. Trabajo de Titulación para optar al título de Ingeniero Civil Industrial. Universidad Austral de Chile. Sede Puerto Montt. 123 pp.

Ríos, S., 2005. Impactos ambientales de la salmonicultura en la Región de los Lagos. Taller de Desarrollo Sustentables. Programa de Magíster en Ciencias Sociales. Ediciones Eumed.net. 34 pp.

Saavedra, M. 2010. Incorporación del concepto de desarrollo sustentable en modelos de sistemas gestión ambiental aplicados en la industria salmonera. Tesis para optar al grado de Magíster en Gestión y Planificación Ambiental. Facultad de ciencias forestales y conservación de la naturaleza. Magíster en gestión y planificación ambiental. Programa interfacultades. Universidad de chile. 227 pp.

Servicio Nacional de Pesca. 2005. Diagnóstico ambiental de la acuicultura chilena en función de los estándares establecidos en el Reglamento Ambiental para la Acuicultura (RAMA). 44 pp.

Silva. N., 2006. Avances en el conocimiento oceanográfico de las aguas interiores chilenas. Comité Oceanográfico Nacional - Pontificia Universidad Católica de Valparaíso, Valparaíso pp. 69-75.

Silva N. y S. Palma. 2006. Avances en el conocimiento oceanográfico de las aguas interiores chilenas. Comité Oceanográfico Nacional - Pontificia Universidad Católica de Valparaíso, Valparaíso pp. 11-15.

Silva N. y E. Quiroga. 2010. Manual de Evaluación de los Informes Ambientales de la Acuicultura. Licitación № 701-47-L110. Servicio de Elaboración de Manual de Evaluación de los Informes ambientales de la acuicultura para el Servicio Nacional de Pesca. Escuela de Ciencias del Mar. Pontificia Universidad Católica de Valparaíso (PUCV) 84 pp.

Subsecretaría de Pesca. 2006. Informe Ambiental de la Acuicultura. Departamento de Acuicultura. 12 pp. Stead, R., y C. Uribe. 2012. Informe variables Sedimentarias Pre y Post Aplicación SRF Centro Detico Granja Marina Tornagaleones. Trabajo no publicado 50 pp.

Taller: Sustentabilidad y Manejo a largo Plazo de la Actividad Acuícola. Materales y Resultados del Taller de Capacidad de Carga. Enero 2010. Puerto Montt. Chile. 42 pp.

Troya C., T. Wigodski, J. Juretić y R. Castro. 2011. Caso AquaChile: Estrategias de crecimiento en un entorno amenazante. Documentos de trabajo. Serie Gestión № 133. Centro de Gestión (CEGES). Departamento de Ingeniería Industrial. Universidad de Chile. 37 pp. 
Uribe C. 2012. Eficacia de Aplicación del Sistema de Recuperación de Fondos (SRF). Informe Final. Trabajo no publicado $32 \mathrm{pp}$.

Sitios en internet visitados:

http://www.mundoacuicola.cl/comun/index.php?modulo=4\&cat=3\&view=1\&idnews=57278\&especial= http://elpinguino.com/noticias/141237/Prevn-100-nuevas-concesiones-salmoneras-en-Magallanes http://web.sofofa.cl/Noticias/fusion-marine-harvest-cermaq-concentraria-20-de-concesiones-en-chile/ http://www.salmonxpert.cl/?page_id=147\&article_id=98347

http://www.elciudadano.cl/2012/06/27/54298/salmoneros-aprontan-instalaciones-al-interior-deparque-nacional-en-magallanes/

http://radio.uchile.cl/2013/08/22/escepticismo-ante-inclusion-al-g15-salmonero-de-empresas-queoperan-en-chile

http://www.chilepotenciaalimentaria.cl/content/view/241556/Crisis-del-virus-ISA-aumenta-demandade-concesiones-para-salmoneras-en-zona-de-Magallanes.html http://www.visionmaritima.com.uy/vision-maritima/index.php/comercio-exterior/4790-chile-evaluapolitica-regulatoria-de-concesiones-acuicolas

http://www.aqua.cl/noticias/?doc $=47245$

http://www.olca.cl/oca/chile/region11/salmoneras50.htm http://www.farodevigo.es/economia/2013/06/29/gestor-pesca-chile-vendera-granjas/837304.html http://www.terram.cl/index.php?option=com_content\&task=view\&id=11074

http://www.visionacuicola.cl/articulo.shtml?ia=4527\&t=victor-hugo-puchi:-queremos-una-industriamas-segura-no-importa-que-se-pierdan-concesiones

http://www.agromeat.com/45616/chile-incrementara-patentes-acuicolas-para-empresas-salmoneras http://www.pulso.cl/noticia/empresa-mercado/empresa/2012/12/11-15668-9-marine-harvest-estariaad-portas-de-sellar-compra-de-salmonera-en-chile.shtml 
Sustainability, Agri, Food and Environmental Reasearch 2(1): 1-35, 2013.

http://www.salmonex.com/?p=2336\&lang=es

http://sitiocero.net/2013/salmozombies-chilenos-muertos-caminando/

http://www.radiopolar.com/noticia_16080.html 